$\begin{array}{ll}\text { Research Square } & \begin{array}{l}\text { Preprints are preliminary reports that have not undergone peer review. } \\ \text { They should not be considered conclusive, used to inform clinical practice, } \\ \text { or referenced by the media as validated information. }\end{array}\end{array}$

\title{
Association Between Food Insecurity and Key Metabolic Risk Factors for Diet- Sensitive Non-Communicable Diseases in Sub-Saharan Africa: A Systematic Review and Meta-Analysis
}

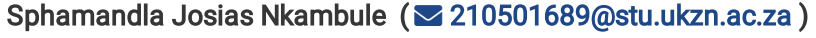 \\ University of KwaZulu-Natal https://orcid.org/0000-0001-7770-6931 \\ Indres Moodley \\ University of KwaZulu-Natal School of Nursing and Public Health \\ Desmond Kuupiel \\ University of KwaZulu-Natal School of Nursing and Public Health \\ Tivani P. Mashamba-Thomson \\ University of KwaZulu-Natal School of Nursing and Public Health
}

\section{Research}

Keywords: Food Insecurity, Metabolic Syndrome, sub-Saharan Africa, Metabolic Risk Factors, Hypertension, Dyslipidemia, Obesity

Posted Date: April 20th, 2020

DOI: https://doi.org/10.21203/rs.3.rs-23105/v1

License: (c) (1) This work is licensed under a Creative Commons Attribution 4.0 International License. Read Full License

Version of Record: A version of this preprint was published at Scientific Reports on March 4th, 2021. See the published version at https://doi.org/10.1038/s41598-021-84344-0. 


\section{Abstract}

\section{Background}

In previous studies, food insecurity has been hypothesised to promote the prevalence of metabolic risk factors on the causal pathway to diet-sensitive noncommunicable diseases (NCDs). This prevalence has been shown to differ between gender and populations. However, evidence of this association in resources-limited settings with high levels of food insecurity such as sub-Saharan African countries remains elusive.

\section{Purpose}

We aimed to identify the association between food insecurity and key metabolic risk factors on the causal pathway to diet-sensitive NCDs in sub-Saharan African population.

\section{Methods}

We did a systematic review according to the Preferred Reporting Items for Systematic Reviews and Meta-Analysis (PRISMA) guidelines. Relevant studies published between January 2015 and October 2019 were searched in PubMed, Web of Science (SCiELO Citation Index), and five other databases followed by explicit and reproducible hand-searches of included studies which were peer-reviewed epidemiological studies conducted in sub-Saharan Africa, directly measured food insecurity, and compared food insecurity to a metabolic risk factor outcome. Two reviewers extracted all the necessary data from individual studies independently and employed the Mixed Methods Appraisal Tool (MMAT) - Version 2018 to evaluate the risk of bias. Prevalence estimates from individual studies were pooled using the random-effect model.

\section{Results}

The initial searches yielded 11803 articles, 22 were eligible for inclusion, presenting data from 26609 food-insecure participants and 11545 incident of metabolic risk factor cases. Most studies confirmed an adverse association between food insecurity and key metabolic risk factors for diet-sensitive NCDs. The Meta-analysis showed a significantly high pooled prevalence estimate of key metabolic risk factors at 41.8 per cent $\left(95 \% \mathrm{Cl}: 33.2 \%\right.$ to $50.8 \%, \mathrm{I}^{2}=99.5 \% \mathrm{p}$ value $<0.00)$. The most prevalent type of metabolic risk factors was dyslipidaemia 27.6 per cent (95\% Cl: $6.5 \%$ to $54.9 \%)$, hypertension 24.7 per cent ( $95 \% \mathrm{Cl}$ : $15.6 \%$ to $35.1 \%$ ), and overweight 15.8 per cent (95\% Cl: $10.6 \%$ to $21.7 \%)$. Notably, the prevalence estimates of these metabolic risk factors were considerably more frequent in females than males.

\section{Conclusion}

This study is the first to systematically review or meta-analyse the association between food insecurity and key metabolic risk factors for diet-sensitive noncommunicable diseases (NCDs) in sub-Saharan African countries, in order to generate an integrated, evidence-based, comprehensive summary of how key metabolic risk factors are patterned by food insecurity. Further high-quality longitudinal data and mediation analysis are warranted to understand the basis of this findings to support targeted prevention and control strategies for those confronted with food insecurity.

\section{PROSPERO registration number: PROSPERO 2019 CRD42019136638}

\section{Background}

Metabolic risk factors are accelerating rapidly and advancing across countries. Globally, this results in a substantial morbidity and mortality burden, linked to diet-sensitive non-communicable diseases (NCDs) such as diabetes and cardiovascular diseases. ${ }^{1,2}$ In 2017, metabolic risk factors claimed an estimated 10.4 million deaths, and approximately 218 million disability-adjusted life-years (DALYs). ${ }^{3}$ Thus, due to their large contribution to global disease burden, rapid increasing trends and variable patterns across countries, has prompted researcher to investigate factors driving the prevalence of metabolic risk factors. One such factor is food insecurity, defined as the lack of access to nutritionally adequate foods caused by poverty and other socio-economic stressors. ${ }^{4-7}$

The World Health Organization (WHO) and the United Nations General Assembly, among other professional organisations, recently identified food insecurity as an important proximate driver of the prevalence of metabolic risk factors on the causal pathway to diet-sensitive NCDs. ${ }^{8}$ This premise is rooted in the hypothesis that exposure to food insecurity results in compensatory behaviours, which often includes less intake of fruit and vegetables, ${ }^{9}$ skipping meals, or reducing portion sizes, ${ }^{10}$ and overconsumption of low-cost foods that are high in calories yet deficient in nutritional value. ${ }^{11}$ Over time, these compensatory behaviours, perceived as buffers against food insecurity, may lead to malnutrition, which, in turn, initiates a cascade of metabolic risk factors that ultimately precipitate diet-sensitive NCDs. ${ }^{8,12,13}$

However, previous studies on the association between food insecurity and metabolic risk factors have yielded conflicting evidence of associations, especially for children and adult males, ${ }^{14}$ whereas more persuasive evidence of an antagonistic relationship was found in women from high-income countries. ${ }^{11,15}$ Evidence of this association in resources-limited settings with high levels of food insecurity such as the sub-Saharan African countries has not been systematically reviewed or meta-analysed, to generate an integrated, evidence-based, comprehensive summary of how key metabolic risk factors are patterned by food insecurity among the populace confronted with food insecurity.

We then conducted a systematic review and meta-analysis with the objective to use accumulated evidence published between January 2015 and June 2019 , to identify the associations between food insecurity and key metabolic risk factors for diet-sensitive NCDs, and to investigate the reliability of associations by 
evaluating the prevalence patterns by study population characteristics - including visualizing variation patterns in occurrence of metabolic risk factors by age, gender, geographic area and research methodological quality.

We hypothesised that the pooled prevalence of the key metabolic risk factors would be higher among food-insecure participants when compared to the general population of sub-Saharan Africa, because malnutrition is the central feature in the pathogenesis of metabolic risk factors. The study findings may serve as baseline data is essential for setting priorities, designing interventions to reduce associated morbidity and mortality, and to strengthen the basis for policy action and recommendations for future research.

\section{Methodology}

Study Design

Before undertaking this systematic review and meta-analysis, a protocol was developed and registered with the International Prospective Register of Systematic Reviews (PROSPERO; CRD42019136638), made accessible to the public via the link below:

https://www.crd.york.ac.uk/prospero/display_record.php?ID=CRD42019136638

The systematic review and meta-analysis were chosen as the best method to explore the association between food insecurity and metabolic risk factors on the causal pathway to diet-sensitive non-communicable diseases (NCDs), and to quantify the prevalence of key metabolic risk factors patterned by food insecurity in the sub-Saharan African populations. This systematic review and meta-analysis was guided by the Preferred Reporting Items for Systematic Reviews and Meta-Analysis (PRISMA) guidelines, ${ }^{16}$ - seven steps: identifying the research question, eligibility criteria, identification of eligible studies, study selection, data extraction, risk of bias assessment, and data analysis. The PRISMA guidelines were observed throughout the design, implementation, analysis, and reporting of this review findings.

In this review, The Mixed Methods Appraisal Tool(MMAT) - Version 2018 was employed to evaluate the methodological quality of all eligible studies chosen for inclusion. ${ }^{17}$ Additionally, the presence of publication bias was assessed by examining the funnel plots for asymmetry. ${ }^{18}$

\section{Step 1: Identifying the research question}

The main research question: What is the association between food insecurity and key metabolic risk factors for diet-sensitive NCDs in sub-Saharan African population?

To determine the eligibility of our research question for a systematic review study, the PEO (Population, Exposure, and Outcomes) nomenclature was used, ${ }^{19}$ as illustrated in Table 1.

\section{Step 2: Eligibility criteria}

The eligibility criteria were developed according to the relevant elements of the PEO-T (Time) framework guidance for undertaking this review. Eligible articles were included after two reviewers had independently, reproducibly, and systematically evaluated them and met the inclusion criteria, as illustrated in Table 2 .

\section{Step 3: Identification of eligible studies}

\section{a) Search strategy and terms guide}

Before undertaking the primary searches in electronic databases, comprehensive search strategies were co-developed by a subject specialist and professional university librarian and reviewed by all authors to ensure the correct use of terminology and descriptors. The search strategy was pre-tested with a subset of records from the PubMed database during the initial pilot test of the proposed eligibility criteria. It was then tailored to the syntax and subject headings of all other consulted databases. Details of the search strategy descriptors used, and the number of returned records are presented in Table 4 in the Supplementary Appendix No.1.

\section{b) Literature search methods}

Identification of eligible studies for inclusion in this review was through a comprehensive and reproducible electronic search of reputable bibliographic databases (and platforms), followed by hand-searching. Article identification and selection in all searched bibliographic databases (and platforms) were performed simultaneously by the first author with the assistance of a professional university librarian for a month, between May and June 2019.

Electronic Search - We identified studies on the association between food insecurity and metabolic risk factors, from comprehensive searches conducted in the following electronic bibliographic databases (and platforms): PubMed, EBSCOhost (CINAHL with full text, Health Source - Nursing, MedLine), Ovid (Journals@Ovid Full Text), Web of Science (SCiELO Citation Index), and Google Scholar platforms which uses a range of databases to elicit relevant recent studies. The first author also used the 'related articles' option to detect more studies across electronic bibliographic databases. The publication date was limited from January 2015 to October 2019. No language restrictions were imposed to minimize the risk that eligible studies could be inadvertently excluded.

Hand-Search - Furthermore, in order to obtain extra relevant recent studies not captured by our comprehensive search strategy, we hand searched the bibliographies (reference lists) of all eligible studies for inclusion and the previously published systematic reviews of relevant topic. Lastly, the subject specialist, medical professionals and university librarian in the field were contacted for relevant studies. 
All searches were conducted until 28 June 2019. The records of retrieved articles through electronic databases and hand-searches were exported into a reference manager software, EndNote X9 (version 19.1.0.12691) virtual library. The virtual library was created specifically for this study for removing duplicates of the same records, screening, and study selection.

\section{Step 4: Study selection}

Study selection was a multi-step process which involved two reviewers. The reviewers screened each article retrieved from the primary searches separately, reproducibly, and systematically for eligibility, utilizing three predefined sets of screening checklist/tools (Supplementary Appendix No. 2 - Google Forms). All three sets of the screening checklist/tools were tested for reliability and applicability.

The study selection procedure or screening of articles for eligibility was carried out in compliance with the Preferred Reporting Items for Systematic Reviews and Meta-Analysis (PRISMA) guidelines and summarized as a flow diagram in Figure $1 .^{16}$ The selection procedure involved three screening stages:

Title Screening - The first author with the assistance of a professional librarian, retrieved literature articles with relevant titles as guided by PEO framework and study eligibility criteria (Table 2) from the following electronic bibliographic databases (and platforms): PubMed, EBSCOhost (CINAHL with full text, Health Source - Nursing, MedLine), Ovid (Journals@Ovid Full Text), Web of Science (SCiELO Citation Index), and Google Scholar platforms which uses a range of databases.

Abstract Screening - Following title screening, retrieved literature articles with relevant titles were exported to the EndNote X9 (version 19.1.0.12691) software. Two independent reviewers conducted abstract article screening from the included literature articles, being guided by the study eligibility criteria. Differences between reviewers at this stage were settled through reaching a consensus among reviewers.

Full Article Screening - This stage was conducted like the abstract screening stage. Full-text articles were retrieved where studies met the inclusion criteria, further establishing the eligibility. At this stage, a third screener was consulted to resolve differences.

The excluded articles at each screening stage were stored in a different EndNote X9 virtual library, and reasons for exclusion of studies were documented (see Figure 1). The degree of agreement was assessed using the kappa statistic, which is a robust statistic used for inter-rater reliability testing (see Table 6 Supplementary Appendix No. 1). ${ }^{20}$

\section{Step 5: Data extraction}

A standardised data extraction form, in a Google Form format, was specifically developed, based on a checklist presented in the Cochrane Handbook for Systematic Reviews of Interventions. ${ }^{21}$ It was calibrated and pre-tested for reliability and applicability with a subset of records from the excluded studies for consistency across reviewers, before implementation.

\section{a) Data item and extraction procedure}

In order to establish an inter-rater and to avoid data errors, the data extraction procedure involved two reviewers who independently extracted all the necessary data from all included studies. For additional information, missing data or uncertainties, authors of the included studies were contacted by e-mail, where needed, with a maximum of three attempts. The studies concerned were excluded after three unsuccessful attempts to contact the author. A full list of data items extracted from each of the included studies is presented in the Supplementary Appendix No. 2 of the Data Extraction Form.

The coordinator resolved disagreements between the two reviewers, and the decision was either taken to have a third reviewer to re-examine the study, or to extract all the necessary data from the studies concerned, guided by the same extraction process as outlined above.

\section{Step 6: Risk of bias assessment}

The methodological quality (internal and external validity as well as the risk of bias) for all included primary studies was evaluated using the Mixed Methods Appraisal Tool (MMAT) - Version 2018. ${ }^{17}$ The summary of the domains considered in the assessment of the scientific quality and risk of bias is presented in the Supplementary Appendix No. 2 file. Two reviewers independently performed the quality assessment. Differences in rating results were resolved by discussion until consensus was reached. An overall percentage quality score was calculated for included studies, and scores were interpreted as of low quality if $\leq 50$ per cent - average quality if $51-75$ per cent - and high quality if $76-100$ per cent. Studies were not excluded based on quality, but quality scores were presented descriptively.

\section{Step 7: Data analysis and synthesis of results}

After extracting all the necessary data from each article selected for inclusion, a summary of extracted data, i.e., baseline characteristics and significant findings, was compiled in a table by the authors. Based on the country of origin, studies selected for inclusion were grouped and narratively synthesised according to the four geographical regions of sub-Saharan Africa, namely Central Africa, Western Africa, Southern Africa, and Eastern Africa. The researchers then used Canva, an interactive web-based graphic design tool, to model an African map showing the four regions where the included studies and the number of study participants were located. ${ }^{22}$

\section{a) Primary outcomes of interest and measures}


The primary outcome of the study was to critically evaluate the current evidence on the association between food insecurity and key metabolic risk factors on the causal pathway to diet-sensitive NCDs, independent of socio-demographic characteristics. The evidence on the associations between food insecurity and metabolic risk factors was narratively synthesised and presented in the compiled summary of the extracted data table, see Table 3. The pooled associations between food insecurity and key metabolic risk factors from each study selected for inclusion were categorised according to the following criteria:

a. [-] Adverse - Food insecurity was reported to be significantly associated with $\geq$ one key metabolic risk factor;

b. [+] Non-significant - There was no significant association found between food insecurity and reported key metabolic risk factors, and

c. [ ] Inconclusive - The association between food insecurity and reported metabolic risk factors was inconclusive because, although exposure to food insecurity showed a protective effect toward reported metabolic risk factors, it was not statistically significant.

Furthermore, metabolic risk factors' prevalence estimates for the populace experiencing food insecurity derived from each study selected for inclusion stratify the risk of diet-sensitive NCDs for that population. Therefore, evidence of the prevalence estimates (\%) of key metabolic risk factors, i.e., obesity, hypertension, underweight, dyslipidaemia, and overweight among the populace confronted with food insecurity, including variability in incidence by age, sex, or region was the secondary outcome of interest. The derived prevalence estimates were obtained by dividing the number of participants who were diagnosed with any of the key metabolic risk factors per the international diagnostic criteria for MetS, by the total number of participants who have been included in the study (Sample Size), then multiplying by 100 .

\section{b) Meta-analysis}

Following the narrative synthesis of each study selected for inclusion, meta-analyses were performed to obtain pooled prevalence estimates. The eligible studies were summarised and presented by using a forest plot. Studies with low risk of bias and outcomes deemed to be sufficiently homogenous were selected for inclusion in the meta-analysis to compute the pooled prevalence estimates. The pooled analyses were carried out using MetaXL version 5.3 statistical software (EpiGear International, Sunrise Beach, Queenland, Australia). ${ }^{23}$

In the meta-analysis of prevalence, the meta-weighted prevalence of metabolic risk factors among the pooled participants ( $95 \%$ confidence interval) was calculated using a random-effect model, as we predicted heterogeneity in the prevalence estimates from different studies. ${ }^{23}$ The observed heterogeneity between study estimates was analysed using the $\mathrm{I}^{2}$ figures, i.e., the percentage of variance not due to studies-wide sampling error, where the significance was considered as per the guidelines of the Cochrane Handbook for Systematic Reviews of Interventions. ${ }^{21}$ Consequently, an $\mathrm{I}^{2}$ value $\geq 75$ per cent indicated a strong heterogeneity. Prevalence estimates were stratified by gender and geographical regions.

\section{c) Principal summary measures}

The chief summary measures included odds ratios (ORs), percentages (\%), 95 per cent confidence intervals ( $95 \% \mathrm{Cl}$ ). The primary effect measure of interest was the pooled prevalence estimates (\%), and the overall synthesised measure of the effect size of food insecurity on key metabolic risk factors for dietsensitive NCDs calculated as odds ratio (OR), with 95 per cent confidence intervals $(95 \% \mathrm{Cl})$. In comparison, reliability between raters was measured using Cohen's Kappa (range) and a score of $<0$ was deemed low, $0.01-0.20$ was considered to be minor, $0.21-0.40$ was deemed to be fair, $0.41-0.60$ was deemed to be mild, $0.61-0.80$ was deemed to be significant, and $0.81-1.00$ was considered to be great. A statistically significant p-value of less than 0.05 was considered.

\section{Results}

\section{Screening results}

The initial electronic bibliographic database searches yielded 11803 potentially eligible articles (Supplementary Appendix No. 1 Table 4). Following title screening, 10918 articles were excluded, and 885 met the eligibility criteria (Figure 1) and were exported to the EndNote X9 (version 19.1.0.12691) virtual library explicitly created for this study. Hand-searching yielded 19 articles that could not be captured by the search strategy, which were also exported to EndNote X9 virtual library. A total of 105 duplicates was removed from the library, leaving 799 articles eligible for abstract screening. Following abstract screening, 93 articles were considered suitable for thorough assessment in full-article screening, during which 71 of them were excluded. Full-article screening yielded 22, which were selected for inclusion in data extraction and were included in the current systematic review. Nineteen articles were included in the metaanalysis. All articles were included in the narrative synthesis. See Figure 1 for the PRISMA flow chart detailing the study selection and exclusion process.

After the full-article screening, we measured the degree of the agreement (see Table 6 in the Supplementary Appendix No. 1). The results showed that there was a 92.5 per cent agreement versus 62.2 per cent expected by chance, which constitutes a considerably high agreement between screeners (Kappa statistic $=-0.80$ and $p$-value $<0.05$ ). Also, the McNemar's chi-square statistic suggests that there is no statistically significant difference in the proportions of yes/no answers by reviewers with $p$-value $>0.05$.

\section{Risk of bias assessment}

All 22 primary studies eligible for inclusion, were subjected to a methodological quality assessment utilizing the Mixed Methods Appraisal Tool (MMAT) Version 2018. ${ }^{17}$ The studies were evaluated using all the considered domains. Once all the studies were assessed, three were rated 100 per cent, six as 86 per cent, twelve as 71 per cent, and one as 57 per cent (see Table 5 in the Supplementary Appendix No. 1). Nine of the 22 included studies were therefore deemed high quality $(75-100 \%$ score). We could not explore publication bias by examining the funnel plots for asymmetry, because, in the presence of high heterogeneity, there is no reason to expect a plot of estimates against their SEs to have a funnel shape. 


\section{Characteristics of Included Studies}

In total, 22 studies were retained for analysis, 20 studies contributed data for children (00-14 years), youths (15-24 years) and adults (25-64 years), and only 2 studies contributed data for seniors ( $\geq 65$ years). The baseline characteristics and significant findings of the included studies are presented in Table 3 .

\section{a) Study participants and geographical setting}

All twenty-two included studies were cross-sectional by design, and each of the studies focused on the different geographic settings, distributed across four regions of the sub-Saharan Africa (see Figure 2). A large proportion of the studies ( $n=10$ studies) was conducted in urban settings, ${ }^{24-33}$ and four studies were conducted in rural settings only. ${ }^{34-37}$ One study was conducted in a peri-urban ${ }^{38}$ and one study in a semi-rural setting. ${ }^{39}$ The remaining six studies recruited participants from both rural and urban settings. ${ }^{40-45}$

Overall, the studies selected for inclusion ( $n=22$ studies) involved a total of 26609 participants, $12453(46.8 \%)$ participants were males, and one study recruited only women of reproductive age living in informal settlements in Accra, Ghana ${ }^{29}$. The distribution of the rest of the studies by countries was as follows: 4 from Ethiopia, ${ }^{25,27,40,41}$; 1 Nigeria ${ }^{24}$; 1 Madagascar, ${ }^{26} ; 3$ Ghana, ${ }^{29,} 38,39 ; 1$ Zambia, ${ }^{37} ; 2$ Tanzania, ${ }^{28,35 ;}, 1$ Malawi, ${ }^{34} ; 1$ Cameroon, ${ }^{33} ; 2$ Sudan, ${ }^{30,31} ; 1$ Burkina Faso, ${ }^{42} ; 1$ Kenya, ${ }^{32} ; 1$ Botswana, ${ }^{45}$ and 3 studies from South Africa ${ }^{36,43,44}$. Figure 2 shows the study distribution from the four regions of subSaharan Africa, with only 1 study from Central Africa ${ }^{33}$ and 12 from Eastern Africa.

\section{b) Food Insecurity}

In assessing food insecurity exposure in the original publication, across the twenty-two included studies, this was generally measured either at a household level or at an individual level and indicated categorically. In this group of studies, a subset ( $\mathrm{n}=3$ studies) involved designs where researchers measured food insecurity at the household level using the food insecurity access scale criterion. ${ }^{22,37,40}$ Another subset $(n=9$ studies) measured food insecurity at an individual level using the Minimum Adequate Diet criterion, $24,25,27,31,33,36,37,42,43$ the Minimum Dietary Diversity criterion ( $n=5$ studies), ${ }^{28,29,38,39,45}$ and the last subset ( $n=4$ studies) used more than one tool to gauge food insecurity. ${ }^{30,37,44,45}$ While studies on children $\leq 5$ years used the Minimum Meal Frequency criterion, ${ }^{30}$ the Weight-for-height criterion, ${ }^{34}$ and the Quetelet index ${ }^{26}$ to ascertain food insecurity. See Table 1 in the Supplementary Appendix No. 1 for a detailed list of reported tools/ methods definitions and theoretical minimum risk exposure level/ scales used to ascertain food insecurity for each study.

\section{c) Metabolic Risk Factors}

Collectively, the included studies presented prevalence data on a variety of metabolic risk factors, using a total of nine international diagnostic criteria to diagnose metabolic risk factors (see Table 2 in the Supplementary Appendix No. 1). In the current review, the WHO STEPwise approach to chronic disease risk factor surveillance diagnostic criteria was found to be the most used diagnostic tool ( $\mathrm{n}=8$ studies); $24,25,27-29,36,37,42$ while self-reported pretested questionnaire followed by a physical examination to confirm condition was the second most used diagnostic tool ( $\mathrm{n}=5 \mathrm{studies)} .{ }^{30,33,38,40,41}$ One study on seniors $\geq 60$ years used the WHO Global Aging and Adult Health (SAGE) criteria to diagnose for metabolic risk factors. ${ }^{43}$

\section{Results of Individual Studies}

\section{a) Evidence on the associations between food insecurity and metabolic risk factors}

In summary, all twenty-two included studies contributed strong evidence on the association between food insecurity and key metabolic risk factors on the causal pathway to diet-sensitive NCDs in children (00-14 years), youths (15-24 years), adults (25-64 years), and senior ( $\geq 65$ years) participants pooled across sub-Saharan African countries ( $\mathrm{n}=9$ studies of high quality $75-100 \%, \mathrm{n}=13$ of average quality $51-75 \%)$ (Table 3).

Twenty of the included studies ( $n=8$ studies of high quality $75-100 \%$, and $n=12$ of average quality $51-75 \%$ ) consistently suggested an adverse association between reported key metabolic risk factors and exposure to food insecurity, that is, seven studies on children (00-14 years), four studies on the youth (15-24 years), seven studies on adults (25-64 years), and two studies on the senior ( $\geq 65$ years) participants, as shown in Table 3.

Of the two remaining studies, Gebremichael et al. ${ }^{41}$ ( $n=1$ of high quality, $86 \%$ ) reported that the was no statistically significant association between hypertension and food insecurity exposure in adults-only study participants. In contrast, Omech et al. ${ }^{45}$ ( $n=1$ of average quality, $71 \%$ in adults-only study participants, found that although consumption of vegetables, fruit, and berries showed a protective effect on dyslipidaemia and obesity, it was not statistically significant; thus the association between dyslipidemia, obesity, and exposure to food insecurity was inconclusive.

\section{b) Prevalence of metabolic risk factors among the pooled study participants}

Furthermore, all twenty-two included studies contributed prevalence estimates data on the spectrum of crucial metabolic risk factors, i.e., obesity, hypertension, underweight, dyslipidaemia and overweight patterned by food insecurity exposure, across four regions of sub-Saharan Africa, including variability in incidence by age, gender, and region. The prevalence estimates of the spectrum of metabolic risk factors pooled from the 22 included studies, varied considerably within gender and geographical regions, as Figure 3 illustrates.

The frequency table (see Table 4) shows the pooled number of participants diagnosed with the various metabolic risk factors relative to the total number diagnosed for males and females. The percentage with respects to these totals is shown in parenthesis. A total of 11545 ( $43,4 \%$ ) out of 26609 food-insecure participants were diagnosed with different metabolic risk factors. 
The prevalence estimates of key metabolic risk factors reported ranged from the lowest in Western Africa, Ghana $(63 / 1165 ; 5.4 \%)^{39}$ to the highest in Southern Africa, South Africa $(1172 / 1403 ; 83.5 \%)^{36}$ (see Table 6 in Supplementary Appendix No. 1). For hypertension (males $28.8 \%$, females $42.5 \%$ ) and obesity (males $6.2 \%$, females $14.2 \%$ ) there were 12 studies conducted in all four regions of sub-Saharan Africa with data that could be pooled.

Dyslipidaemia was reported in four studies (males 7.5\%, females 3.7\%) conducted in Western Africa, Southern Africa, and Eastern Africa. Status as overweight was reported in eight studies (males 7.1\%, females $8.9 \%$ ) conducted in all four regions of the sub-Saharan Africa, while status as underweight was reported in six studies (males 11.3\%, females 3.49\%) among adults' participants in Central Africa, Western Africa, and Eastern Africa. Lastly, the prevalence for stunting (males $38 \%$, females $25 \%$ ), Acute Respiratory Infections (ARI) (males $0.86 \%$, females $0.38 \%$ ), and Left Ventricular Mass (males $0.97 \%$, females $1.16 \%$ ) was reported in four studies conducted in Eastern Africa only, among participants age $\leq$ six years.

There appears to be a slight difference between female participants (44.6\%) who were diagnosed with the different key metabolic risk factors and their male counterparts (42.1\%) who were also diagnosed. The derived prevalence estimates in males ranged from the lowest (134/501; $26.75 \%)$ in Central Africa to the highest in $(3001 / 7006 ; 42.83 \%)$ Eastern Africa. Notably, the prevalence estimates of obesity, hypertension, and status as overweight were considerably more frequent in females than males. While dyslipidemia, being underweight and stunting were more prevalent in males (see Figure 3).

\section{Results of Meta-analysis}

Only 19 studies were of sufficient quality for inclusion for meta-analysis. The prevalence estimates were combined across studies using the random-effect model for meta-analysis. The results are summarised and presented in the forest plots (Figure 4 and Figure 5 ). Due to the low number of studies that reported stunting, acute respiratory infection, and left ventricular mass types of metabolic risk factors (less than 3), a meta-analysis could not be undertaken for those studies.

\section{a) Meta-weighted prevalence of underweight and overweight}

The pooled prevalence of being underweight, derived from six studies, was 12.2 per cent ( $95 \% \mathrm{Cl}$ : $7.0 \%$ to $18.5 \%$ ), irrespective of diagnostic criteria (Figure $4 \mathrm{a}$ ). Substantial heterogeneity was detected by $I^{2}$ statistic $\left(I^{2}=97.14 \% p\right.$-value $\left.<0.00\right)$ between each of the six studies. The pooled prevalence of being overweight, derived from seven studies, was 15.8 per cent ( $95 \% \mathrm{Cl}$ : $10.6 \%$ to $21.7 \%$ ) and the observed heterogeneity detected at $\mathrm{I}^{2}=96.89$ per cent $p$-value $<0.00$ respectively (Figure $4 b)$.

\section{b) Meta-weighted prevalence of hypertension, obesity, and dyslipidaemia}

The pooled prevalence of hypertension and obesity, derived from 12 studies was 24.7 per cent (95\% Cl: $15.6 \%$ to $35.1 \%, I^{2}=99.4 \% p$-value < 0.00$)$ (Figure 5 c), and 12.8 per cent ( $95 \% \mathrm{Cl}: 7.4 \%$ to $19.5 \%, \mathrm{I}^{2}=98.85 \% p$-value $<0.00$ ) respectively (Figure $5 \mathrm{~d}$ ). The pooled prevalence of dyslipidaemia, derived from 3 studies was 27.6 per cent ( $95 \% \mathrm{Cl}: 6.5 \%$ to $54.9 \%$ ), heterogeneity was detected by $\mathrm{I}^{2}$ statistic at $\mathrm{I}^{2}=99.18 \% p$-value $<0.00$ (Figure $5 \mathrm{e}$ ).

\section{c) Exploration of heterogeneity}

The overall pooled prevalence estimate of key metabolic risk factors was 41.8 per cent ( $95 \% \mathrm{Cl}: 33.2 \%$ to $50.8 \%$ ), and a high degree of heterogeneity between the 19 studies was detected at $\mathrm{I}^{2}=99.5$ per cent $\mathrm{p}$-value $<0.00$. Sensitivity analyses, an exploration of the possible cause of significant heterogeneity, were not formally conducted, due to the low number of the group of studies reporting on these outcomes, i.e., obesity, hypertension, being underweight, dyslipidaemia and being overweight, providing scant ability to detect them. Hence, there were not enough variations observed in the following study-level characteristics: study quality score, study geographical region, and diagnostic criteria to justify different groupings.

\section{Discussion}

Food insecurity affects approximately more than 257 million (1 in 3) people in sub-Saharan Africa, and it has been hypothesised to promote the prevalence of metabolic risk factors on the causal pathway to diet-sensitive non-communicable diseases (NCDs) in the region. ${ }^{4}$ The objective of this study, was to use accumulated evidence published between January 2015 and June 2019, to identify the associations between food insecurity and key metabolic risk factors for diet-sensitive NCDs, and to investigate the reliability of associations by evaluating the prevalence patterns by study population characteristics - including visualizing variation patterns in occurrence of metabolic risk factors among the populace confronted with food insecurity in sub-Saharan Africa.

By establishing an association between food insecurity and key metabolic risk factors for diet-sensitive NCDs in the sub-Saharan Africa population across a wider age range, we intend to identify an easy-to-obtain and objective screening with which to target the populace confronted with food insecurity who may be at greater risk for diet-sensitive NCDs.

Our systematic review found an adverse association between food insecurity and key metabolic risk factors on the causal pathway to diet-sensitive NCDs measured in children (00-14 years), youths (15-24 years), adults (25-64 years), and senior ( $\geq 65$ years) participants pooled from 22 studies ( $n=9$ studies of high quality $75-100 \%, n=13$ of average quality $51-75 \%$ ) conducted across 12 sub-Saharan African countries.

In the random-effect meta-analyses of 19 of these studies, showed a significantly high overall pooled prevalence estimate of key metabolic risk factors at 41.8 per cent $\left(95 \% \mathrm{Cl}: 33.2 \%\right.$ to $50.8 \%, \mathrm{I}^{2}=99.5 \% \mathrm{p}$-value $<0.00$,). It thus, suggests a significant risk of diet-sensitive NCDs among the populace confronted with food insecurity in sub-Saharan Africa, across all age groups.

\section{Comparison with Previous Studies}


Previous systematic reviews have contributed to the evidence that food insecurity is associated with metabolic risk factors on the causal pathway to dietsensitive NCDs, in the current review, the results of both analyses show imperative similarities and differences with earlier reports. However, at the same time, affirms the need to tackle food insecurity in order to effectively promote population health and the prevention and control of diet-sensitive NCDs in the region. ${ }^{46}$

Similar to our systematic review, Arenas et al. ${ }^{5}$ found an adverse association between exposure to food insecurity and dyslipidemia, reported from 7 peerreviewed manuscripts published between 2006-2015. By contrast, the review by Arenas et al. ${ }^{5}$ found that there is no consistent literature-wide association between body mass index and food insecurity-status; only 18 studies out of 37 reported a statistically significant association, which is more studies than we report in our current review. These findings have implications for research, as the inconsistencies of results across studies merit careful assessment of the various methodologies used in the original studies.

In general, potential sources of inconsistencies across studies may be ascribed mostly to various methodological concerns, relating to the design of the studies, analytical techniques, the diversity of food insecurity and malnutrition indicators used, wide variations in clinical diagnostic criteria for defining metabolic risk factors and, above all, to the limited availability of high-quality micro-level data from large-scale surveys. ${ }^{47-49}$

The random-effect meta-analytic component of this review provides an ability to present estimates of the prevalence of the key metabolic risk factors associated with food insecurity with greater precision. Ahmed et al. ${ }^{50}$ in Saudi Arabia, estimated a comparable overall prevalence of metabolic risk factors of 41.8 per cent from The Africa Middle East Cardiovascular Epidemiological (ACE) study cohort. Earlier community survey reports in other sub-Saharan African countries reported a lower prevalence among adult participants in Ethiopia, Kenya, and South Africa, ranging from 17.9 per cent reported in 2011 to 34.6 per cent reported in 2012, and 30.7 per cent reported in 2014, respectively. ${ }^{51-53}$ Our current review findings add to this evidence of a rapidly growing burden of metabolic risk factors between different populations, indicating a substantial increase in risk for diet-sensitive NCDs in the sub-Saharan Africa region over the years.

Moreover, visualizing variation patterns in occurrence by gender among the pooled food-insecure participants, an almost twofold female-to-male disparity in the prevalence of key metabolic risk factors were observed. Our findings indicate that dyslipidaemia is the most prevalent type of metabolic risk factor among males (7.5\%), but not among females (3.7\%) derived from 3 studies $24,37,45$, with the pooled prevalence estimate of 27.6 per cent (95\% Cl: $6.5 \%$ to $54.9 \%, \mathrm{I}^{2}$ $=99.18 \% \mathrm{p}$-value $<0.00)$. Hypertension was the second most prevalent type of metabolic risk factor with an estimate of 24.7 per cent $(95 \% \mathrm{Cl}: 15.6 \%$ to $35.1 \%$, $I^{2}=99.43 \%$ p-value < 0.00$)$, higher among females (42.5\%) compared to males $(28.8 \%)$, followed by obesity (females $14.2 \%$, males $\left.6.2 \%\right)$, and lastly, being overweight (females $8.9 \%$, males $7.1 \%$ ). These findings have implications for accurate prioritization of food insecurity and metabolic risk factors screening for effective utilization of insufficient health services in resource-limited environments, including sub-Saharan Africa.

These findings are consistent with Motala et al. ${ }^{54}$, who found that the prevalence of metabolic risk factors was higher in rural South African females (25.0\%) than in males (10.5\%). Moreover, these findings somewhat reflect a gender-specific effect of metabolic risk factors discussed among African-American women precipitating diet-sensitive NCDs. ${ }^{55-57}$ In several sub-Saharan African countries ${ }^{37,58,59}$, as well as in the African-American population ${ }^{15,57}$, the higher prevalence of metabolic risk factors in women compared to men has also been identified. However, prevalence estimates from non-African American and other developed nations do not show a clear trend for gender variance in the prevalence of metabolic risk factors $53,57,60$.

Sex differences in health-seeking behaviour, cultural values, positive social perceptions surrounding body weight may be attributed to the apparent gender disparities observed in the prevalence of metabolic risk factors, particularly in the context of sub-Saharan Africa ${ }^{37,61}$. An overweight status/ obesity is socially tolerated or even desired in African cultures, and this might be another explanation of the observed gender-variance. Thus, leading to significantly higher levels of obesity and other metabolic risk factors among females by comparison with males, as observed in the current review. In addition, excess body weight is most recently associated with a lack of HIV/AIDS diseases and stigmatisation ${ }^{53}$.

\section{Strengths and limitations}

The strengths of this review are that its findings are based on only cross-sectional epidemiological studies designed to elucidate whether or not food insecurity status is a predictor of key metabolic risk factors for diet-sensitive NCDs in sub-Saharan Africa. A study protocol was developed before the conduct of the review and pre-registered with a prospective international register of systematic reviews to be made available to the public, thus enhancing our study's transparency.

We adhered exclusively to the Preferred Reporting Items for Systematic Reviews and Meta-Analysis (PRISMA) guidelines to maximise the rigour and robustness of the methodology used in this study throughout its design, implementation, analysis and reporting. The systematic and extensive search strategy used in this study to identify all studies meeting the pre-set eligibility criteria was co-planned and developed by a professional university librarian and a subject specialist. Two reviewers independently and reproducibly assessed primary search results by using a Google Form., i.e., an interactive web-based data management tool to establish an inter-rater and to avoid data errors in the screening, extraction of data and measurement of research quality.

Despite the reported strength of our study, the following limitations need to be considered. The first major limitation of our study was that a significant heterogeneity was observed between studies $\left(l^{2}=99.5\right.$ per cent $p$-value $\left.<0.00\right)$, although we used a random effect model, it was unlikely that the heterogeneity was fully accounted for. Since only a small number of included studies was utilised, there was limited opportunity for exploration of the possible major causes of significant heterogeneity.

The second limitation to our study was that the methods or tools employed across studies to assess food insecurity exposure and clinical diagnostic criteria for defining metabolic risk factors varied, and this might be another explanation for the observed heterogeneity among studies. Despite the level of high 
heterogeneity observed between studies, the pooled prevalence estimates are comparable with those from international surveys and reviews, but this evidence should still be interpreted with caution.

\section{Implications for practice}

The current systematic review findings indicate that exposure to food insecurity is associated with an increase in the prevalence of certain key metabolic risk factors on the causal pathway to diet-sensitive NCDs. In policy terms, there are three critical implications of these findings. Firstly, the prevalence of key metabolic risk factor is high among the populace confronted with food insecurity, particularly in resources-limited settings like the sub-Saharan African countries. Therefore, regular screening is essential to facilitate early detection and intervention, while bearing in mind the crucial need for more cost-effective and efficient screening/ or case-finding strategies for metabolic risk factors in resources-limited settings.

Regular food insecurity status screening and treatment as a preventative medicine tool for diet-sensitive NCDs, is recommended in these settings and the adaptation of a consensus screening checklist may facilitate this goal. This strategy is endorsed by the Academic Paediatrics Association (APA), the National Academy of Medicine, Centers for Disease Control and Prevention, and the World Health Organization, ${ }^{62,63}$ merely because food insecurity status is easily measured without the need of expensive laboratory investigations (paper risk test or anthropometric measurement). Moreover, in the face of limited specialist, primary healthcare workers can be trained to screen for food insecurity status to identify potentially at high-risk individuals for early diagnosis of metabolic risk factors. Thus also adapting already existing healthcare programmes for other diseases such as HIV/AIDS which are well established in many subSaharan African countries for monitoring metabolic risk factors on the causal pathway to diet-sensitive NCDs, may also facilitate this goal.

Secondly, increasing the capacity to monitoring metabolic risk factors on the causal pathway to diet-sensitive NCDs among the populace confronted with food insecurity in sub-Saharan African countries is crucial. Routine screening programmes for food insecurity status and metabolic risk factors are still not a priority in much sub-Saharan African countries, due costly case-finding strategies, laboratory diagnostic tests, and high burden of infectious diseases such as HIV/AIDS. ${ }^{64}$ Thirdly, there is much heterogeneity between males and females in the frequency of metabolic risk factors. This may indicate the need for local prioritisation of health resources and intervention to reflect a gender-specific effect.

Lastly, our cautiously interpreted prevalence estimates can be used in regional, national, and local prevalence calculations of the prevalence of metabolic risk factors to drive public health efforts and prioritisation of metabolic risk factors screening programmes in the general population by health policymakers. Also, our estimates should inspire further research to investigate the cost-effectiveness and efficiency of 'food insecurity status screening and treatment' as a preventative medicine for diet-sensitive NCDs in the sub-Saharan African countries.

\section{Implications for research}

Based on the findings of this review, the recommendations for future research, many of which are consistent with previous surveys, are presented below:

Our study shows that limited published longitudinal cohort studies have been conducted in sub-Saharan African countries, with food insecurity as an exposure and metabolic risk factors as an outcome, indicating a need for more longitudinal study research design. These research studies are desirable for the determination of absolute risk, and the causal link between food insecurity exposures, metabolic risk factors, and diet-sensitive NCDs.

In epidemiological studies investigating the association between food insecurity exposures and metabolic risk factors in humans, it would be beneficial to separate confounders and then subsequently adjust for both confounders and mediators to address the question 'whether or not food insecurity exposures contribute to increased prevalence of metabolic risk factors independently'. It would also help delineate the prevalence of metabolic risk factors attributed to food insecurity exposures, and prevalence increase conferred by interrelated metabolic risk factors (e.g., obesity/overweight leading to hypertension).

Our study also revealed that most of the studies highlighted the unique challenges faced by women, indicating that more research is needed on the qualitative and quantitative associations between food insecurity and metabolic risk factors in men, in particular since exposures to food insecurity and metabolic risk factors can be experienced differently physiologically and psychologically between genders.

\section{Conclusion}

This review has contributed to the evidence that food insecurity status is associated with an increase in the prevalence of certain key metabolic risk factors on the causal pathway to diet-sensitive NCDs. High heterogeneity and imprecision culminated in low quality of evidence to support these associations; however, both analyses findings were found to be of low level of bias.

Therefore, to prevent diet-sensitive NCDs in regions with reported high rates of food insecurity, food insecurity status screening and treatment, as preventative medicine, are recommended. Nevertheless, further high-quality longitudinal data and mediation analysis are warranted to understand the basis of this findings to support targeted prevention and control strategies for those confronted with food insecurity.

\section{Acronyms And Abbreviations}

LMICs Low- and Middle-Income Countries

MMAT Mixed Methods Appraisal Tool

PEO Population, Exposure, and Outcomes

Page $9 / 20$ 
DSCDs Diet-sensitive Chronic Diseases

PRISMA Preferred reporting items for systematic review and meta-analysis

WHO World Health Organization

FAO Food and Agriculture Organization

NCDs Non-communicable diseases

\section{Declarations}

\section{Ethical Approval and Consent to participate}

This paper is a Systematic Review and Meta-analysis study that relied strictly on the review of existing literature, no human participants were involved. Therefore, ethical approval and consent to participate by human participants was not applicable.

\section{Consent for publication}

Not applicable

\section{Availability of supporting data}

The data supporting the conclusions of this paper are available through the detailed reference list. No original datasets are presented, due to the fact that this is a review of already existing literature.

\section{Competing interests}

The authors declare no competing interests.

\section{Funding}

This study was partly funded through the College of Health Sciences Scholarship (University of KwaZulu-Natal, South Africa). The funders had no role in study design, data collection, data analysis, interpretation, or writing of the paper.

\section{Authors' Contributions}

All authors contributed to the conception and design of the systematic literature review, the collection and screening of publications. TPM-T, SJN, and IM contributed to the analysis and interpretation of the findings. SJN drafted the manuscript. TPM-T, DK, and IM reviewed and provided input to revise the manuscript. DK contributed to the statistical analysis (Meta-analysis) and to preparation of the report. All authors gave final approval for submission.

\section{Acknowledgements}

We would like to thank the College of Health Sciences, Department of Public Health Medicine, School of Nursing and Public Health, and the Library Services at the University of KwaZulu-Natal, Durban, South Africa for providing the resources to help us in setting up and conducting this review study.

\section{References}

1. Gakidou E, Afshin A, Abajobir AA, Abate KH, Abbafati C, Abbas KM, et al. Global, regional, and national comparative risk assessment of 84 behavioural, environmental and occupational, and metabolic risks or clusters of risks, 1990-2016: a systematic analysis for the Global Burden of Disease Study 2016. The Lancet. 2017;390(10100):1345-422.

2. Habib SH, Saha S. Burden of non-communicable disease: global overview. Diabetes \& Metabolic Syndrome: Clinical Research \& Reviews. 2010;4(1):41-7.

3. Roth GA, Abate D, Abate KH, Abay SMea. Global, regional, and national age-sex-specific mortality for 282 causes of death in 195 countries and territories, 1980-2017: a systematic analysis for the Global Burden of Disease Study 2017. The Lancet. 2018;392(10159):1736-88.

4. FAO I, UNICEF, WFP, WHO. The state of food security and nutrition in the world 2019. Safeguarding against economic slowdowns and downturns. FAO Rome (Italy); 2019.

5. Arenas DJ, Zhou S, Thomas A, Wang J, Arroyo GV, Bash K. Negative health outcomes associated with food insecurity status in the United States of America: A systematic review of peer-reviewed studies. 2018.

6. Faramarzi E, Somi M, Ostadrahimi A, Dastgiri S, Nahand MG, Jafarabadi MA, et al. Association between food insecurity and metabolic syndrome in North West of Iran: Azar Cohort study. Journal of Cardiovascular and Thoracic Research. 2019;11(3):196.

7. Nettle D, Andrews C, Bateson M. Food insecurity as a driver of obesity in humans: The insurance hypothesis. Behavioral and Brain Sciences. 2017;40.

8. Organization WH. The double burden of malnutrition. Policy brief. Geneva: World Health Organization. WHO/NMH/NHD/17; 2017.

9. Jomaa L, Naja F, Cheaib R, Hwalla N. Household food insecurity is associated with a higher burden of obesity and risk of dietary inadequacies among mothers in Beirut, Lebanon. BMC Public Health. 2017;17(1).

10. DECKER D, FLYNN M. Food Insecurity and Chronic Disease: Addressing Food Access as a Healthcare Issue. Rhode Island Medical Journal. 2018;101(4). 
11. Seligman HK, Schillinger D. Hunger and socioeconomic disparities in chronic disease. N Engl J Med. 2010;363(1):6-9.

12. Mahmoodi MR, Najafipour $\mathrm{H}$, Mohsenpour MA, Amiri M. The relationship between food insecurity with cardiovascular risk markers and metabolic syndrome components in patients with diabetes: A population-based study from Kerman coronary artery disease risk study. Journal of research in medical sciences: the official journal of Isfahan University of Medical Sciences. 2017;22.

13. Laraia BA. Food Insecurity and Chronic Disease. Advances in Nutrition. 2013;4(2):203-12.

14. Eisenmann JC, Gundersen C, Lohman BJ, Garasky S, Stewart SD. Is food insecurity related to overweight and obesity in children and adolescents? A summary of studies, 1995-2009. Obesity Reviews. 2011;12(5):e73-e83.

15. Rochlani Y, Pothineni NV, Mehta JL. Metabolic syndrome: does it differ between women and men? Cardiovascular drugs and therapy. 2015;29(4):329-38.

16. Liberati A, Altman DG, Tetzlaff J, Mulrow C, Gøtzsche PC, loannidis JP, et al. The PRISMA statement for reporting systematic reviews and meta-analyses of studies that evaluate health care interventions: explanation and elaboration. PLoS medicine. 2009;6(7):e1000100.

17. Hong QN, Pluye P, Fàbregues S, Bartlett G, Boardman F, Cargo M, et al. Mixed methods appraisal tool (MMAT), version 2018. IC Canadian Intellectual Property Office, Industry Canada. 2018.

18. Debray TP, Moons KG, Riley RD. Detecting small-study effects and funnel plot asymmetry in meta-analysis of survival data: A comparison of new and existing tests. Research synthesis methods. 2018;9(1):41-50.

19. Moola S, Munn Z, Sears K, Sfetcu R, Currie M, Lisy K, et al. Conducting systematic reviews of association (etiology): The Joanna Briggs Institute's approach. International journal of evidence-based healthcare. 2015;13(3):163-9.

20. McHugh ML. Interrater reliability: the kappa statistic. Biochemia medica: Biochemia medica. 2012;22(3):276-82.

21. Higgins JP, Deeks JJ. Selecting studies and collecting data. Cochrane Handbook for Systematic Reviews of Interventions: Cochrane Book Series. 2008:151-85.

22. Melanie Perkins COCA. About canva - Launches A Graphic Design Platform Anyone Can Use: @canva; 2019 [Available from: http://about.canva.com/.

23. Barendregt JJ, Doi SA. MetaXL user guide. Version. 2016;4:2011-6.

24. Agaba E, I, Maxwell OA, Edith NO, Patricia AA, Amaka NO, Zumnan MG, et al. A survey of non-communicable diseases and their risk factors among university employees: a single institutional study. Cardiovascular journal of Africa. 2017;28(6):377.

25. Anteneh ZA, Gedefaw M, Tekletsadek KN, Tsegaye M, Alemu D. Risk Factors of Overweight and Obesity among High School Students in Bahir Dar City, North West Ethiopia: School Based Cross-Sectional Study. Advances in Preventive Medicine. 2015;2015:1-9.

26. Di Gioia G, Creta A, Fittipaldi M, Giorgino R, Quintarelli F, Satriano U, et al. Effects of Malnutrition on Left Ventricular Mass in a North-Malagasy Children Population. PLOS ONE. 2016;11(5):e0154523.

27. Desalew A, Mandesh A, Semahegn A. Childhood overweight, obesity and associated factors among primary school children in dire dawa, eastern Ethiopia; a cross-sectional study. BMC Obesity. 2017;4(1).

28. Katalambula L, Petrucka P, Buza J, Ngoma T. Colorectal Cancer Epidemiology in Tanzania: Patterns in Relation to Dietary and Lifestyle Factors. American Society of Clinical Oncology; 2018.

29. Lapauw B. DIETARY PATTERN AND METABOLIC SYNDROME AMONG URBAN SLUM WOMEN, ACCRA GHANA: University of Health and Allied Sciences; 2016.

30. Musaiger AO, Al-Khalifa F, Al-Mannai M. Obesity, unhealthy dietary habits and sedentary behaviors among university students in Sudan: growing risks for chronic diseases in a poor country. Environmental health and preventive medicine. 2016;21(4):224-30.

31. Musaiger AO, Nabag FO, Al-Mannai M. Obesity, Dietary Habits, and Sedentary Behaviors Among Adolescents in Sudan. Food and Nutrition Bulletin. 2016;37(1):65-72.

32. Mutisya M, Kandala N-B, Ngware MW, Kabiru CW. Household food (in)security and nutritional status of urban poor children aged 6 to 23 months in Kenya. BMC Public Health. 2015;15(1).

33. Nansseu JR, Kameni BS, Assah FK, Bigna JJ, Petnga S-J, Tounouga DN, et al. Prevalence of major cardiovascular disease risk factors among a group of sub-Saharan African young adults: a population-based cross-sectional study in Yaoundé, Cameroon. BMJ Open. 2019;9(10):e029858.

34. Cox M, Rose L, Kalua K, De Wildt G, Bailey R, Hart J. The prevalence and risk factors for acute respiratory infections in children aged 0-59 months in rural Malawi: A cross-sectional study. Influenza and Other Respiratory Viruses. 2017;11(6):489-96.

35. Kejo D, Mosha TCE, Petrucka P, Martin H, Kimanya ME. Prevalence and predictors of undernutrition among underfive children in Arusha District, Tanzania. Food Science \& Nutrition. 2018;6(8):2264-72.

36. Maimela E, Alberts M, Modjadji SEP, Choma SSR, Dikotope SA, Ntuli TS, et al. The Prevalence and Determinants of Chronic Non-Communicable Disease Risk Factors amongst Adults in the Dikgale Health Demographic and Surveillance System (HDSS) Site, Limpopo Province of South Africa. PLOS ONE. 2016;11(2):e0147926.

37. Tateyama Y, Techasrivichien T, Musumari PM, Suguimoto SP, Zulu R, Macwan'Gi M, et al. Obesity matters but is not perceived: A cross-sectional study on cardiovascular disease risk factors among a population-based probability sample in rural Zambia. PLOS ONE. 2018;13(11):e0208176.

38. Mohammed H, Ghosh S, Vuvor F, Mensah-Armah S, Steiner-Asiedu M. Dietary intake and the dynamics of stress, hypertension and obesity in a periurban community in Accra. Ghana Medical Journal. 2016;50(1):16.

39. Colecraft EK, Asante M, Christian AK, Adu-Afarwuah S. Sociodemographic Characteristics, Dietary Practices, and Nutritional Status of Adults with Hypertension in a Semi-Rural Community in the Eastern Region of Ghana. International Journal of Hypertension. 2018;2018:1-7. 
40. Abebe SM, Andargie G, Shimeka A, Alemu K, Kebede Y, Wubeshet M, et al. The prevalence of non-communicable diseases in northwest Ethiopia: survey of Dabat Health and Demographic Surveillance System. BMJ Open. 2017;7(10):e015496.

41. Gebremichael GB, Berhe KK, Zemichael TM. Uncontrolled hypertension and associated factors among adult hypertensive patients in Ayder comprehensive specialized hospital, Tigray, Ethiopia, 2018. BMC Cardiovascular Disorders. 2019;19(1).

42. Soubeiga JK, Millogo T, Bicaba BW, Doulougou B, Kouanda S. Prevalence and factors associated with hypertension in Burkina Faso: a countrywide crosssectional study. BMC Public Health. 2017;17(1).

43. Mbaissouroum M. Risk Factors of High Blood Pressure in Older South Africans: Southern Connecticut State University; 2017.

44. Solomons N, Kruger HS, Puoane T. Association between dietary adherence, anthropometric measurements and blood pressure in an urban black population, South Africa. South African Journal of Clinical Nutrition. 2018:1-9.

45. Omech B, Tshikuka J-G, Mwita J, Tsima B, Nkomazana O, Amone_P' Olak K. Prevalence and determinants of metabolic syndrome: a cross-sectional survey of general medical outpatient clinics using National Cholesterol Expanded Program-Adult Treatment Panel III criteria in Botswana. Diabetes, Metabolic Syndrome and Obesity: Targets and Therapy. 2016;Volume 9:273-9.

46. Mendis S, Davis S, Norrving B. Organizational update: the world health organization global status report on noncommunicable diseases 2014; one more landmark step in the combat against stroke and vascular disease. Stroke. 2015;46(5):e121-e2.

47. Flegal KM, Ogden CL. Childhood obesity: are we all speaking the same language? Advances in nutrition. 2011;2(2):159S-66S.

48. Sone H, Tanaka S, Ishibashi S, Yamasaki Y, Oikawa S, Ito H, et al. The new worldwide definition of metabolic syndrome is not a better diagnostic predictor of cardiovascular disease in Japanese diabetic patients than the existing definitions: additional analysis from the Japan Diabetes Complications Study. Diabetes care. 2006;29(1):145-7.

49. Sardinha LB, Santos DA, Silva AM, Grøntved A, Andersen LB, Ekelund U. A comparison between BMI, waist circumference, and waist-to-height ratio for identifying cardio-metabolic risk in children and adolescents. PLoS One. 2016;11(2):e0149351.

50. Ahmed AM, Hersi A, Mashhoud W, Arafah MR, Abreu PC, Al Rowaily MA, et al. Cardiovascular Risk Factors Burden in Saudi Arabia: The Africa Middle East Cardiovascular Epidemiological (ACE) Study. 2017.

51. Tran A, Gelaye B, Girma B, Lemma S, Berhane Y, Bekele T, et al. Prevalence of metabolic syndrome among working adults in Ethiopia. International journal of hypertension. 2011;2011.

52. Kaduka LU, Kombe Y, Kenya E, Kuria E, Bore JK, Bukania ZN, et al. Prevalence of metabolic syndrome among an urban population in Kenya. Diabetes Care. 2012;35(4):887-93.

53. Peer N, Lombard C, Steyn K, Levitt N. High prevalence of metabolic syndrome in the Black population of Cape Town: The Cardiovascular Risk in Black South Africans (CRIBSA) study. European Journal of Preventive Cardiology. 2015;22(8):1036-42.

54. Motala AA, Esterhuizen T, Pirie FJ, Omar MA. The prevalence of metabolic syndrome and determination of the optimal waist circumference cutoff points in a rural South African community. Diabetes care. 2011;34(4):1032-7.

55. Moreira GC, Cipullo JP, Ciorlia LAS, Cesarino CB, Vilela-Martin JF. Prevalence of metabolic syndrome: association with risk factors and cardiovascular complications in an urban population. PloS one. 2014;9(9):e105056.

56. Okafor $\mathrm{Cl}$. The metabolic syndrome in Africa: Current trends. Indian journal of endocrinology and metabolism. 2012;16(1):56.

57. Krishnamoorthy A, Greiner MA, Bertoni AG, Eapen ZJ, O'Brien EC, Curtis LH, et al. The obesity and heart failure epidemics among African Americans: insights from the Jackson Heart study. Journal of cardiac failure. 2016;22(8):589-97.

58. Crowther NJ, Norris SA. The current waist circumference cut point used for the diagnosis of metabolic syndrome in sub-Saharan African women is not appropriate. PloS one. 2012;7(11):e48883.

59. Adeiza M, Yusuf R, Liman A, Abur P, Bello F, Abba A. Tuberculosis of the breast: an initial presentation of the metabolic syndrome with type 2 diabetes mellitus in a young Nigerian woman. Case reports in infectious diseases. 2016;2016.

60. Scuteri A, Laurent S, Cucca F, Cockcroft J, Cunha PG, Mañas LR, et al. Metabolic syndrome across Europe: different clusters of risk factors. European journal of preventive cardiology. 2015;22(4):486-91.

61. Renzaho AMN. Fat, rich and beautiful: changing socio-cultural paradigms associated with obesity risk, nutritional status and refugee children from subSaharan Africa. Health \& Place. 2004;10(1):105-13.

62. Tong ST, Liaw WR, Kashiri PL, Pecsok J, Rozman J, Bazemore AW, et al. Clinician Experiences with Screening for Social Needs in Primary Care. The Journal of the American Board of Family Medicine. 2018;31(3):351.

63. Chiu S, Okafor M. Challenges and strategies in the implementation of a two-item food insecurity screening tool in primary care. Education for Primary Care. 2019;30(1):52-4.

64. Wang W, Lee ET, Howard BV, Devereux R, Zhang Y, Stoner JA. Large Cohort Data Based Cost-Effective Disease Prevention Design Strategy: Strong Heart Study. World Journal of Cardiovascular Diseases. 2018;08(12):588-601.

\section{Tables}

Table 1: PEO framework for determining the eligibility of the research question 
Population Human participants of all-age groups residing in sub-Saharan Africa, both genders, and regardless of their ethnic background.

Exposure Food Insecurity (FI)* (Independent Variable) experienced at either household or individual level

Outcomes Diagnosed with any of the following key metabolic risk factors for diet-sensitive NCDs per the international diagnostic criteria for metabolic sysndrome (MetS) such as NCEP-ATPIII (2001), International Diabetes Foundation (IDF 2005), AHA/NHLBI criteria (2004), and any other measures in line with the World Health Organization criteria (1998). Outcomes of interest are:

1. Obesity

2. Dyslipidaemia

3. Hypertension

4. Underweight

5. Overweight

6. Others (as reported per study)

Note: *Detailed list of essential tools used to define/ or ascertain food insecurity as an independent variable, accompanying theoretical minimum risk exposure level see Supplementary Appendix No. 1 Table 1

Definition of review outcomes reported assessment beyond general health self-report and the diagnostic criteria for identifying metabolic risk factors for this study see Supplementary Appendix No. 1 Table 2

Table 2: Eligibility criteria according to study design, PEO-T nomenclature criteria

\begin{tabular}{|c|c|}
\hline Criteria & Inclusions \\
\hline $\begin{array}{l}\text { Study } \\
\text { Design }\end{array}$ & $\begin{array}{l}\text { Only original, peer-reviewed cross-sectional studies conducted in } \\
\text { sub-Saharan Africa, by trained personnel in publication language. }\end{array}$ \\
\hline \multirow[t]{3}{*}{ Population } & Studies conducted among sub-Saharan African populations \\
\hline & $\begin{array}{l}\text { Participants of any age group and sex that did not mix the age } \\
\text { groups for analysis }\end{array}$ \\
\hline & Any ethnicity, culture, or race \\
\hline \multirow[t]{3}{*}{ Exposure } & $\begin{array}{l}\text { Studies reporting a measure of food insecurity or food insufficiency } \\
\text { as an independent variable. }\end{array}$ \\
\hline & $\begin{array}{l}\text { A measure of food insecurity beyond receiving government- } \\
\text { sponsored nutritional benefits/ or living in an area designated as a } \\
\text { food desert. }\end{array}$ \\
\hline & Food insecurity evaluated at the household level or individual level. \\
\hline
\end{tabular}

Outcomes Studies reporting at least one of the key metabolic risk factors as a dependent variable.

\section{Exclusions}

Qualitative study design, and systematic reviews, literature reviews, mini-reviews and cross-sectional studies conducted outside of Africa.

Research studies conducted among people outside of sub-Saharan Africa

Participants with coexisting medical conditions

Diagnosed with key metabolic risk factors per any of the international diagnostic criteria for MetS: NCEP-ATP III, IDF, or AHA/NHLBI criteria

Research studies reporting on voluntary food restriction, as in cases of anorexia/Nervosa.

Complete peer-reviewed original research studies, published between

$\begin{array}{ll}\text { Time } & \text { Complete peer-reviewed origin } \\ \text { January } 2015 \text { and June } 2019\end{array}$

Table 3: Characteristics of 22 included studies marching eligibility criteria, reporting the association between food insecurity and key metabolic risk factors in sub-Saharan Africa 


\begin{tabular}{|c|c|c|c|c|c|c|c|}
\hline \multirow{2}{*}{$\begin{array}{l}\text { Author, } \\
\text { Publication } \\
\text { Year }\end{array}$} & \multirow{2}{*}{$\begin{array}{l}\text { Country, } \\
\text { Geographical } \\
\text { Setting }\end{array}$} & \multirow{2}{*}{$\begin{array}{l}\text { Population } \\
\text { Details, Age (v) }\end{array}$} & \multicolumn{2}{|c|}{ Sample Size, Gender } & \multicolumn{2}{|c|}{ Method of Ascertainment } & \multirow{2}{*}{$\begin{array}{l}\text { Signi } \\
\text { Ther } \\
\text { diagi }\end{array}$} \\
\hline & & & & & Food Insecurity & $\begin{array}{l}\text { Criterion for } \\
\text { Diagnosis }\end{array}$ & \\
\hline \multirow[t]{2}{*}{ Abebe, 201740} & \multirow{2}{*}{$\begin{array}{l}\text { Ethiopia, Rural \& } \\
\text { Urban }\end{array}$} & \multirow{2}{*}{$\begin{array}{l}\text { All permanent } \\
\text { residents of the } \\
\text { HDSS site, } \geq 1 \\
\text { year }\end{array}$} & \multirow[t]{2}{*}{1160} & $M-35.3 \%$ & \multirow{2}{*}{$\begin{array}{l}\text { Food Insecurity } \\
\text { Access Scale }\end{array}$} & \multirow{2}{*}{$\begin{array}{l}\text { Self-reported - 'Yes' } \\
\text { when asked whether } \\
\text { they 'ever had } \\
\text { clinician diagnosed } \\
\text { HTN?' }\end{array}$} & \multirow[t]{2}{*}{ Hypertension } \\
\hline & & & & $F-4.7 \%$ & & & \\
\hline \multirow[t]{2}{*}{ Agaba, $2017^{24}$} & \multirow[t]{2}{*}{ Nigeria, Urban } & \multirow{2}{*}{$\begin{array}{l}\text { All employees of } \\
\text { the university, } \geq \\
18 \text { years }\end{array}$} & 883 & $M-59.0 \%$ & \multirow{2}{*}{$\begin{array}{l}\text { Minimum } \\
\text { Adequate Diet }\end{array}$} & \multirow{2}{*}{$\begin{array}{l}\text { The WHO STEPwise } \\
\text { approach to chronic } \\
\text { disease risk factor } \\
\text { surveillance }\end{array}$} & \multirow[b]{2}{*}{ Dyslipidaemi } \\
\hline & & & & $F-41.0 \%$ & & & \\
\hline \multirow{2}{*}{$\begin{array}{l}\text { Anteneh, } 2015 \\
25\end{array}$} & \multirow[t]{2}{*}{ Ethiopia, Urban } & \multirow{2}{*}{$\begin{array}{l}\text { School } \\
\text { adolescents, } 10 \text { - } \\
24 \text { years }\end{array}$} & \multirow[t]{2}{*}{431} & $M-41.1 \%$ & \multirow{2}{*}{$\begin{array}{l}\text { Minimum } \\
\text { Adequate Diet }\end{array}$} & \multirow{2}{*}{$\begin{array}{l}\text { The WHO STEPwise } \\
\text { approach to chronic } \\
\text { disease risk factor } \\
\text { surveillance }\end{array}$} & \multirow[t]{2}{*}{ Obesity } \\
\hline & & & & $F-58.9 \%$ & & & \\
\hline \multirow{2}{*}{$\begin{array}{l}\text { Colecraft, } 2018 \\
39\end{array}$} & \multirow[t]{2}{*}{ Ghana, Semi-Rural } & \multirow{2}{*}{$\begin{array}{l}\text { Residents of } \\
\text { Asesewa in the } \\
\text { Upper Manya } \\
\text { Krobo District, } \geq \\
25 \text { years }\end{array}$} & \multirow[t]{2}{*}{1165} & $M-44.0 \%$ & \multirow{2}{*}{$\begin{array}{l}\text { Minimum Dietary } \\
\text { Diversity }\end{array}$} & \multirow{2}{*}{$\begin{array}{l}\text { The physical } \\
\text { examination to } \\
\text { confirm hypertension } \\
\text { diagnosis completed } \\
\text { by a nurse }\end{array}$} & \multirow[t]{2}{*}{ Hypertension } \\
\hline & & & & $F-56.0 \%$ & & & \\
\hline \multirow[t]{2}{*}{ Cox, $2016^{34}$} & \multirow[t]{2}{*}{ Malawi, Rural } & \multirow{2}{*}{$\begin{array}{l}\text { Children in rural } \\
\text { Monkey Bay, } \leq \\
\text { five years }\end{array}$} & 828 & $M-62.2 \%$ & \multirow{2}{*}{$\begin{array}{l}\text { Weight-for height is } \\
\text { used as an indicator of } \\
\text { nutritional status }\end{array}$} & \multirow{2}{*}{$\begin{array}{l}\text { Integrated } \\
\text { Management of } \\
\text { Childhood Illness } \\
\text { (IMCI) guidelines by } \\
\text { doctors }\end{array}$} & Acute Respira \\
\hline & & & & $F-37.8 \%$ & & & \\
\hline $\begin{array}{l}\text { Desalew, } 2017 \\
27\end{array}$ & Ethiopia, Urban & $\begin{array}{l}\text { Primary school } \\
\text { children, } 11-15\end{array}$ & 448 & M - $41.7 \%$ & $\begin{array}{l}\text { Minimum Adequate } \\
\text { Diet }\end{array}$ & $\begin{array}{l}\text { The WHO Obesity } \\
\text { and Overweight fact }\end{array}$ & $\begin{array}{l}\text { Obesity, } \\
\text { Overweight ar }\end{array}$ \\
\hline & & years & & F - $58.3 \%$ & & sheet & Underweight \\
\hline
\end{tabular}

\begin{tabular}{|c|c|c|c|c|c|c|c|}
\hline $\begin{array}{l}\text { Di Gioia, } 2016 \\
26\end{array}$ & $\begin{array}{l}\text { Madagascar, } \\
\text { Urban }\end{array}$ & $\begin{array}{l}\text { Enrolled children } \\
\text { who came for } \\
\text { routine visits, } 4-6 \\
\text { years }\end{array}$ & 313 & $\begin{array}{l}M-47 \% \\
F-53 \%\end{array}$ & $\begin{array}{l}\text { Malnutrition status } \\
\text { according to BMI/ } \\
\text { Quetelet index }\end{array}$ & $\begin{array}{l}\text { An echocardiographic } \\
\text { evaluation performed } \\
\text { by a doctor }\end{array}$ & $\begin{array}{l}\text { left ventricula } \\
\text { mass }\end{array}$ \\
\hline
\end{tabular}

\begin{tabular}{|c|c|c|c|c|c|c|c|}
\hline $\begin{array}{l}\text { Gebremichael, } \\
2019^{41}\end{array}$ & $\begin{array}{l}\text { Ethiopia, Rural \& } \\
\text { Urban }\end{array}$ & $\begin{array}{l}\text { Hypertensive } \\
\text { patients in a } \\
\text { specialized } \\
\text { hospital, } \geq 18 \\
\text { years }\end{array}$ & 320 & $\begin{array}{l}M-48.8 \% \\
F-51.2 \%\end{array}$ & $\begin{array}{l}\text { Low level of adherence } \\
\text { to DASH - A score of } 6 \\
\text { or better }\end{array}$ & $\begin{array}{l}\text { Self-care practice } \\
\text { adopted from } \\
\text { hypertension self- } \\
\text { care activity level } \\
\text { effects (H-scale) }\end{array}$ & Hypertension \\
\hline $\begin{array}{l}\text { Soubeiga, } 2017 \\
42\end{array}$ & $\begin{array}{l}\text { Burkina Faso, } \\
\text { Rural \& Urban }\end{array}$ & $\begin{array}{l}\text { Nationally } \\
\text { Representative } \\
\text { Sample, } 25 \text { to } 64 \\
\text { years }\end{array}$ & 4,629 & $\begin{array}{l}M-48.2 \% \\
F-51.8 \%\end{array}$ & $\begin{array}{l}\text { Minimum Adequate } \\
\text { Diet }\end{array}$ & $\begin{array}{l}\text { The WHO STEPwise } \\
\text { approach to chronic } \\
\text { disease risk factor } \\
\text { surveillance }\end{array}$ & $\begin{array}{l}\text { Hypertension } \\
\text { Obesity, and } \\
\text { Underweight }\end{array}$ \\
\hline
\end{tabular}

\begin{tabular}{|c|c|c|c|c|c|c|c|}
\hline \multirow{2}{*}{$\begin{array}{l}\text { Katalambula, } \\
2018^{28}\end{array}$} & \multirow{2}{*}{$\begin{array}{l}\text { Tanzania, } \\
\text { Urban }\end{array}$} & \multirow{2}{*}{$\begin{array}{l}\text { Retrospective } \\
\text { chart audit } \\
\text { study in two } \\
\text { national } \\
\text { hospitals, 26- } \\
65 \text { years }\end{array}$} & \multirow[t]{2}{*}{1450} & $M-47.2 \%$ & \multirow{2}{*}{$\begin{array}{l}\text { Minimum } \\
\text { Dietary } \\
\text { Diversity }\end{array}$} & \multirow{2}{*}{$\begin{array}{l}\text { Patient charts indicating a } \\
\text { diagnosis of CRC per the ICD-10 - } \\
\text { WHO Version for } 2016\end{array}$} & \multirow{2}{*}{$\begin{array}{l}\text { Hypertension, } \\
\text { Obesity, and } \\
\text { overweight }\end{array}$} \\
\hline & & & & F - $52.8 \%$ & & & \\
\hline \multirow[t]{2}{*}{ Kejo, $2018^{35}$} & \multirow{2}{*}{$\begin{array}{l}\text { Tanzania, } \\
\text { Rural }\end{array}$} & \multirow{2}{*}{$\begin{array}{l}\text { Residents of } \\
\text { Arusha } \\
\text { District, } \leq 5 \\
\text { years }\end{array}$} & \multirow[t]{2}{*}{436} & $M-32.2 \%$ & \multirow{2}{*}{$\begin{array}{l}\text { Self-reported } \\
\text { 'yes' to practice } \\
\text { of exclusive } \\
\text { breastfeeding }\end{array}$} & \multirow{2}{*}{$\begin{array}{l}\text { Anthropometric data were } \\
\text { collected through the } \\
\text { measurement of length/height } \\
\text { and weight of all children }\end{array}$} & \multirow{2}{*}{$\begin{array}{l}\text { Underweight, } \\
\text { and Stunting }\end{array}$} \\
\hline & & & & $F-23.2 \%$ & & & \\
\hline
\end{tabular}




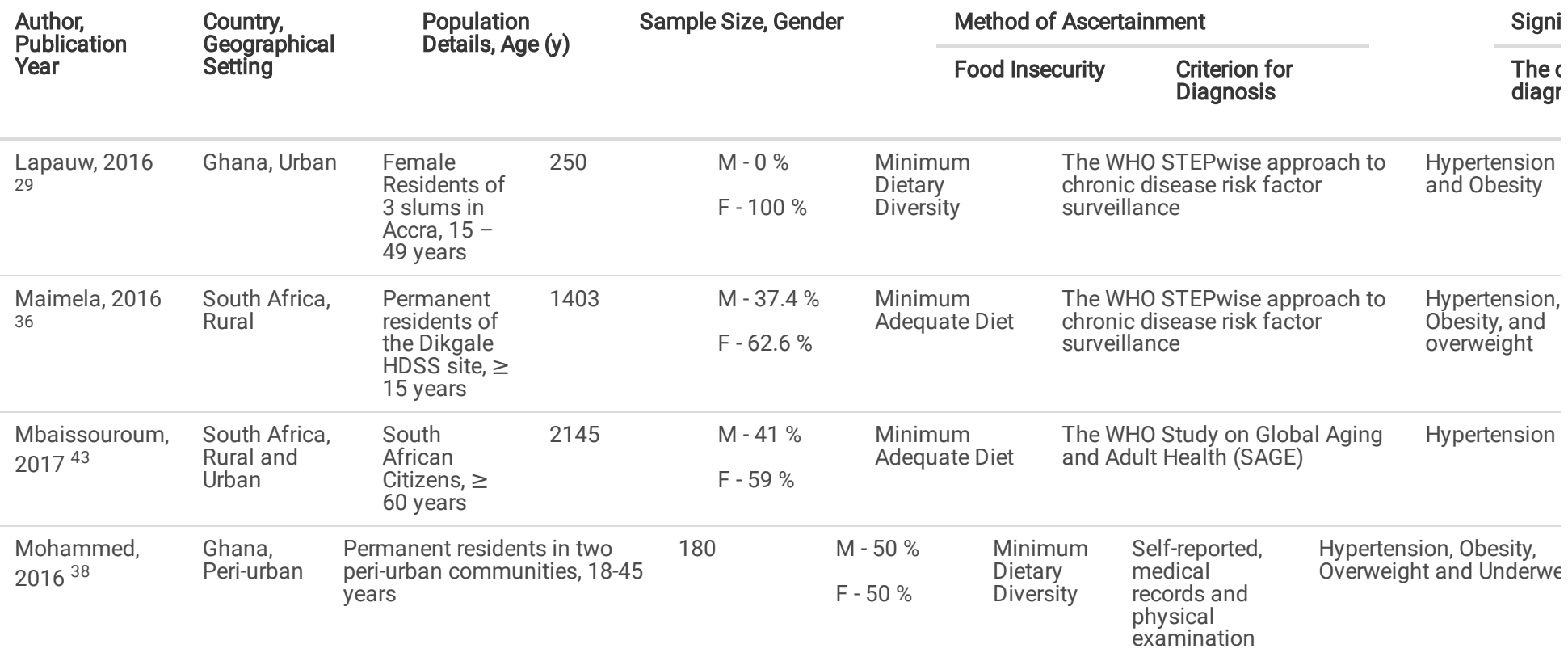

\begin{tabular}{|c|c|c|c|c|c|c|c|}
\hline $\begin{array}{l}\text { Musaiger, } 2016 \\
30\end{array}$ & $\begin{array}{l}\text { Sudan, } \\
\text { Urban }\end{array}$ & $\begin{array}{l}\text { University students in the } \\
\text { College of Education, } 18 \text { to } 30 \\
\text { years }\end{array}$ & 400 & $\begin{array}{l}M-45.8 \% \\
F-54.3 \%\end{array}$ & $\begin{array}{l}\text { Minimum } \\
\text { Meal } \\
\text { Frequency, } \\
\text { Adequate } \\
\text { Diet }\end{array}$ & $\begin{array}{l}\text { Self-reported \& } \\
\text { Anthropometric } \\
\text { measurement }\end{array}$ & $\begin{array}{l}\text { Obesity, Overweight and } \\
\text { Underweight }\end{array}$ \\
\hline
\end{tabular}

\begin{tabular}{|c|c|c|c|c|c|c|c|}
\hline $\begin{array}{l}\text { Musaiger, } 2016 \\
31\end{array}$ & $\begin{array}{l}\text { Sudan, } \\
\text { Urban }\end{array}$ & $\begin{array}{l}\text { Schoolchildren in public } \\
\text { schools aged } 14 \text { to } 18 \text { years }\end{array}$ & 945 & $\begin{array}{l}M-53.7 \% \\
F-46.4 \%\end{array}$ & $\begin{array}{l}\text { Minimum } \\
\text { Adequate } \\
\text { Diet }\end{array}$ & $\begin{array}{l}\text { The } \\
\text { International } \\
\text { Obesity Task } \\
\text { Force standard }\end{array}$ & Obesity and Overweight \\
\hline
\end{tabular}

\begin{tabular}{|c|c|c|c|c|c|c|c|}
\hline $\begin{array}{l}\text { Mutisya, } 2015 \\
32\end{array}$ & $\begin{array}{l}\text { Kenya, } \\
\text { Urban }\end{array}$ & $\begin{array}{l}\text { All women of reproductive } \\
\text { health who are residents, } \leq 5 \\
\text { years }\end{array}$ & 6858 & $\begin{array}{l}M-53.7 \% \\
F-43.9 \%\end{array}$ & $\begin{array}{l}\text { Food } \\
\text { Insecurity } \\
\text { Access } \\
\text { Scale }\end{array}$ & $\begin{array}{l}\text { Z-Scores for } \\
\text { the HFA using } \\
\text { the 'WHO Child } \\
\text { Growth Charts }\end{array}$ & Stunting \\
\hline
\end{tabular}

\begin{tabular}{|c|c|c|c|c|c|c|c|}
\hline $\begin{array}{l}\text { Solomons, } \\
2018^{44}\end{array}$ & $\begin{array}{l}\text { South } \\
\text { Africa, } \\
\text { Rural and } \\
\text { Urban }\end{array}$ & $\begin{array}{l}\text { All residents of Langa, the } \\
\text { urban PURE study site in the } \\
\text { Western Cape province, } 32 \text { to } \\
81 \text { year }\end{array}$ & 454 & $\begin{array}{l}M-24.9 \% \\
F-75.1 \%\end{array}$ & $\begin{array}{l}\text { Minimum } \\
\text { Adequate } \\
\text { Diet, Low } \\
\text { adherence } \\
\text { to DASH }\end{array}$ & $\begin{array}{l}\text { Self-care } \\
\text { practice } \\
\text { adopted from } \\
\text { hypertension } \\
\text { self-care } \\
\text { activity level } \\
\text { effects (H- } \\
\text { scale) }\end{array}$ & Hypertension \\
\hline $\begin{array}{l}\text { Omech, } 2016 \\
45\end{array}$ & $\begin{array}{l}\text { Botswana, } \\
\text { Rural and } \\
\text { Urban }\end{array}$ & $\begin{array}{l}\text { Outpatients aged } \geq 20 \text { years } \\
\text { without a diagnosis of } \\
\text { diabetes mellitus. }\end{array}$ & 291 & $\begin{array}{l}M-25.8 \% \\
F-74.2 \%\end{array}$ & $\begin{array}{l}\text { Minimum } \\
\text { Dietary } \\
\text { Diversity, } \\
\text { Adequate } \\
\text { Diet }\end{array}$ & $\begin{array}{l}\text { Metabolic } \\
\text { syndrome was } \\
\text { assessed using } \\
\text { the National } \\
\text { Cholesterol } \\
\text { Education } \\
\text { Program-Adult } \\
\text { Treatment } \\
\text { Panel }\end{array}$ & Dyslipidaemia and Obes \\
\hline
\end{tabular}




$\begin{array}{llll}\text { Author, } & \text { Country, } & \text { Population } & \text { Sample Size, Gender } \\ \text { Publication } & \text { Geographical } & \text { Details, Age (y) } & \\ \text { Year } & \text { Setting } & \end{array}$

\begin{tabular}{|c|c|c|c|c|c|c|c|}
\hline real & setting & & & & od insecurity & $\begin{array}{l}\text { Diagnosis } \\
\text { Diteron tor }\end{array}$ & diagr \\
\hline \multirow[t]{2}{*}{$\begin{array}{l}\text { Nansseu, } 2019 \\
33\end{array}$} & \multirow{2}{*}{$\begin{array}{l}\text { Cameroon, } \\
\text { Urban }\end{array}$} & \multirow{2}{*}{$\begin{array}{l}\text { Students aged } 18-35 \text { years, } \\
\text { with no known history of CVD }\end{array}$} & \multirow[t]{2}{*}{931} & $M-53.8 \%$ & \multirow{2}{*}{$\begin{array}{l}\text { Minimum } \\
\text { Adequate } \\
\text { Diet }\end{array}$} & \multirow[b]{2}{*}{$\begin{array}{l}\text { Validated } \\
\text { questionnaires, } \\
\text { clinical } \\
\text { measurements, } \\
\text { and } \\
\text { biochemical } \\
\text { analyses, } \\
\text { including } \\
\text { fasting blood } \\
\text { samples }\end{array}$} & \multirow[t]{2}{*}{$\begin{array}{l}\text { Hypertension, Obesity, } \\
\text { Overweight and Underw }\end{array}$} \\
\hline & & & & F - $-46.2 \%$ & & & \\
\hline
\end{tabular}

\begin{tabular}{|c|c|c|c|c|c|c|c|}
\hline $\begin{array}{l}\text { Tateyama, } \\
2018^{37}\end{array}$ & $\begin{array}{l}\text { Zambia, } \\
\text { Rural }\end{array}$ & $\begin{array}{l}\text { Residents of the Mumbwa } \\
\text { district aged } 25-64 \text { years }\end{array}$ & 690 & $\begin{array}{l}M-48.6 \% \\
F-51.4 \%\end{array}$ & $\begin{array}{l}\text { Minimum } \\
\text { Adequate } \\
\text { Diet, Food } \\
\text { Insecurity } \\
\text { Access } \\
\text { Scale }\end{array}$ & $\begin{array}{l}\text { The WHO } \\
\text { STEPwise } \\
\text { approach to } \\
\text { chronic } \\
\text { disease risk } \\
\text { factor } \\
\text { surveillance }\end{array}$ & $\begin{array}{l}\text { Dyslipidaemia Hypertens } \\
\text { Obesity }\end{array}$ \\
\hline
\end{tabular}

\section{Note:}

[-] Adverse - Food insecurity was reported to be significantly associated with $\geq$ one critical metabolic risk factors.

[+] Non-significant - There was no significant association between food insecurity and reported key metabolic risk factors.

[ ] Inconclusive - The association between food insecurity and reported metabolic risk factors was inconclusive because, although exposure to food insecurity showed a protective effect toward MetS, it was not statistically significant

$*_{n}$ diagnosed - the number of participants diagnosed with reported metabolic risk factor, for male $(\mathrm{M})$ and females $(\mathrm{F})$

Table 4: A qualitative description of key metabolic risk factors prevalence derived from 22 individual studies.

\begin{tabular}{|c|c|c|c|}
\hline \multirow[t]{2}{*}{ Studies Reference } & \multirow[t]{2}{*}{$\begin{array}{l}\text { Reported Type of Metabolic Risk } \\
\text { Factors }\end{array}$} & \multicolumn{2}{|c|}{$\begin{array}{l}\text { Participants diagnosed with Metabolic } \\
\text { Risk Factors }\end{array}$} \\
\hline & & Male (5239) & Female (6306) \\
\hline $\begin{array}{l}\text { ( } n=5 \text { studies of high quality, } n=7 \text { of average quality) } 33,38,29,42,45,36 \\
37,31,30,28,27,25\end{array}$ & Obesity & $326(6.2 \%)$ & $896(14.2 \%)$ \\
\hline ( $n=2$ studies of high quality, $n=1$ of average quality) $24,45,37$ & Dyslipidemia & $395(7.5 \%)$ & $235(3.7 \%)$ \\
\hline $\begin{array}{l}\text { ( } n=6 \text { studies of high quality, } n=6 \text { of average quality) } 33,38,29,42,39,36 \\
37,44,28,43,40,41\end{array}$ & Hypertension & $1509(28.8 \%)$ & $2681(42.5 \%)$ \\
\hline$(n=2 \text { studies of high quality, } n=4 \text { of average quality })^{33}, 38,42,30,35,27$ & Underweight & $592(11.3 \%)$ & $220(3.5 \%)$ \\
\hline $\begin{array}{l}(n=2 \text { studies of high quality, } n=5 \text { of average quality })^{33}, 38,3631,30,28, \\
27\end{array}$ & Overweight & $370(7.1 \%)$ & $561(8.9 \%)$ \\
\hline$(n=2 \text { of average quality })^{35}, 32$ & Stunting & $1991(38.0 \%)$ & $1576(25.0 \%)$ \\
\hline$(n=1 \text { of high quality })^{34}$ & $\begin{array}{l}\text { Acute Respiratory Infections } \\
(\mathrm{ARI})\end{array}$ & $45(0.9 \%)$ & $24(0.4 \%)$ \\
\hline$(n=1 \text { of average quality })^{26}$ & left ventricular mass (LVM) & $51(1.1 \%)$ & $73(1.2 \%)$ \\
\hline
\end{tabular}

\section{Figures}



$(\mathrm{n}=\mathbf{8 8 5})$ $(\mathrm{n}=19)$

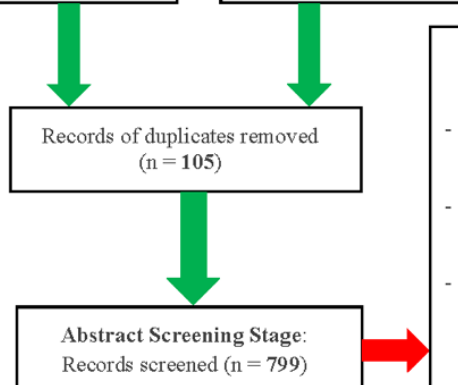

Records excluded $(\mathrm{n}=705)$

( $\mathrm{n}=344)$ Not conducted in

Sub-Saharan Africa

( $n=71$ ) Conducted pre 2015

January

$(n=290)$ No clear definition

of FI exposure and MetS

diagnosis

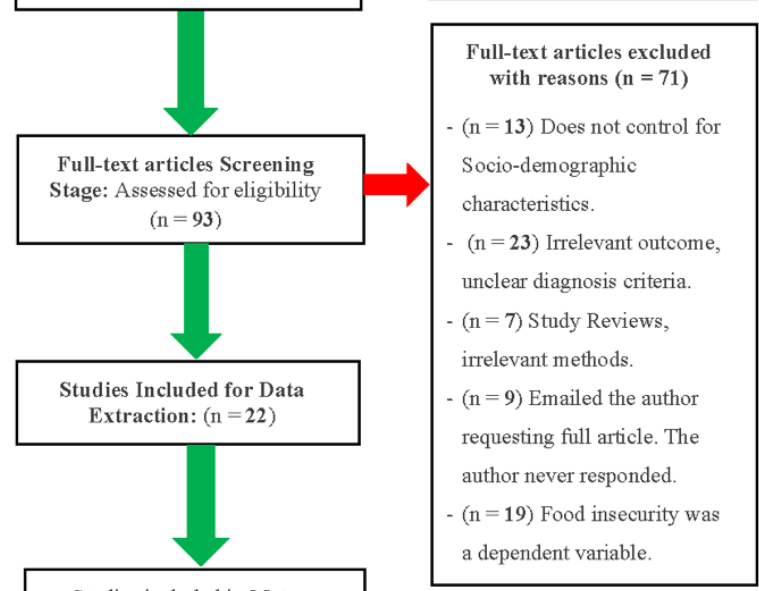

Studies included in Metaanalysis $(n=19)$

\section{Figure 1}

Preferred Reporting Items for Systematic Reviews and Meta-Analysis (PRISMA) flow diagram of literature search and study selection process. 16 


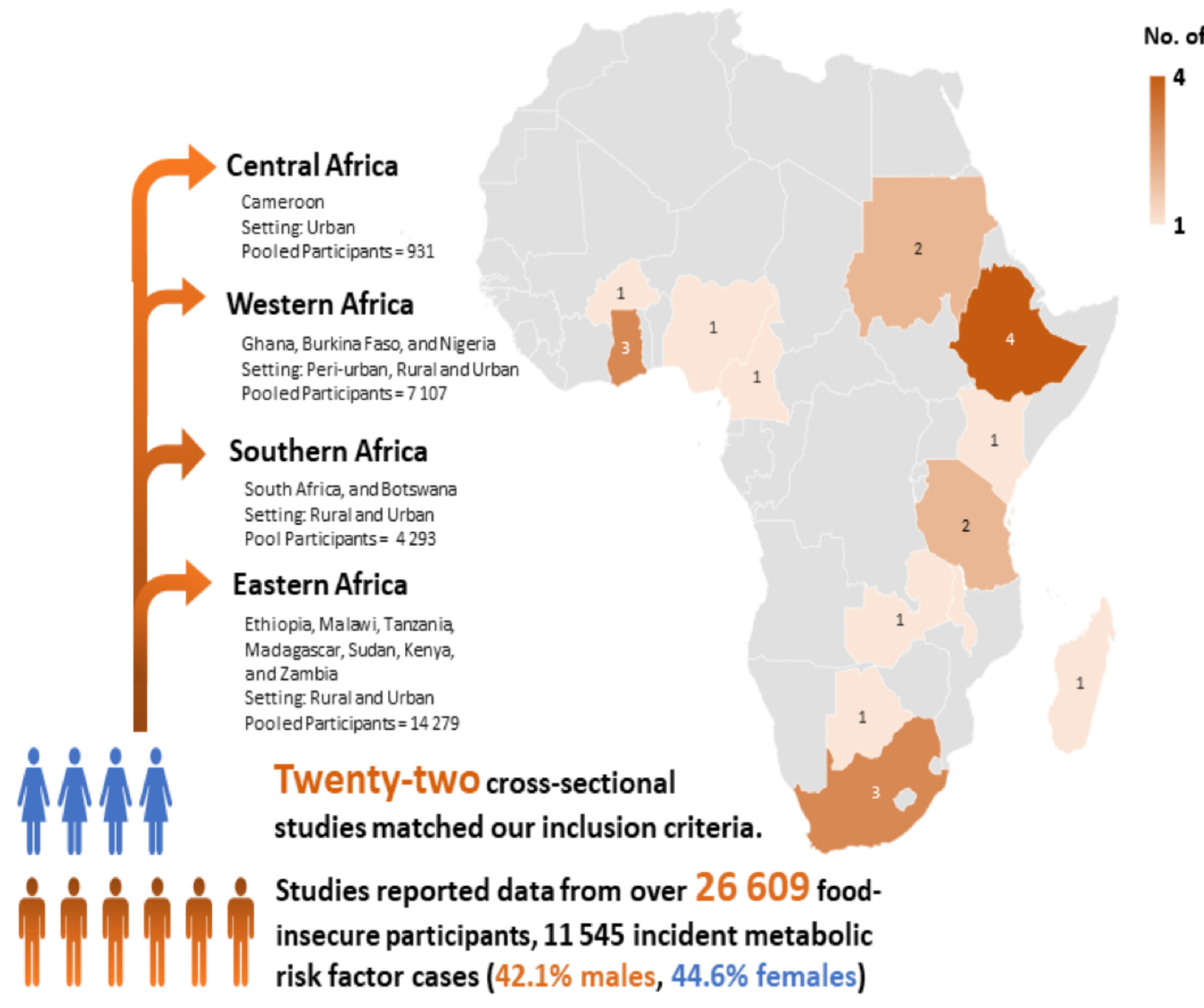

Figure 2

Map of Africa indicating the regions where the included studies were situated and the number of pooled study participants [Figure generated by the first author]. 


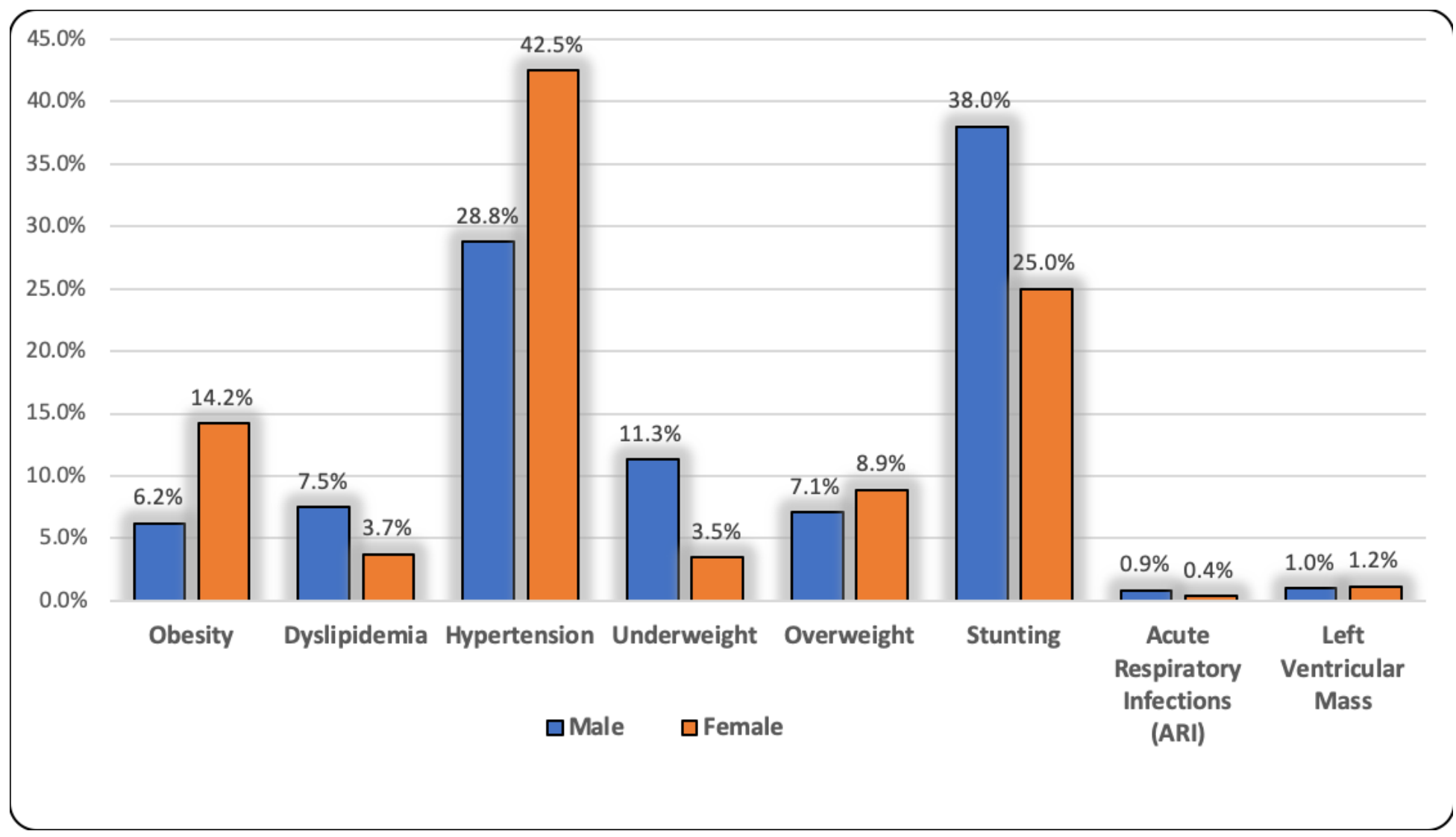

Figure 3

The prevalence of key metabolic risk factors derived from 22 studies by gender strata

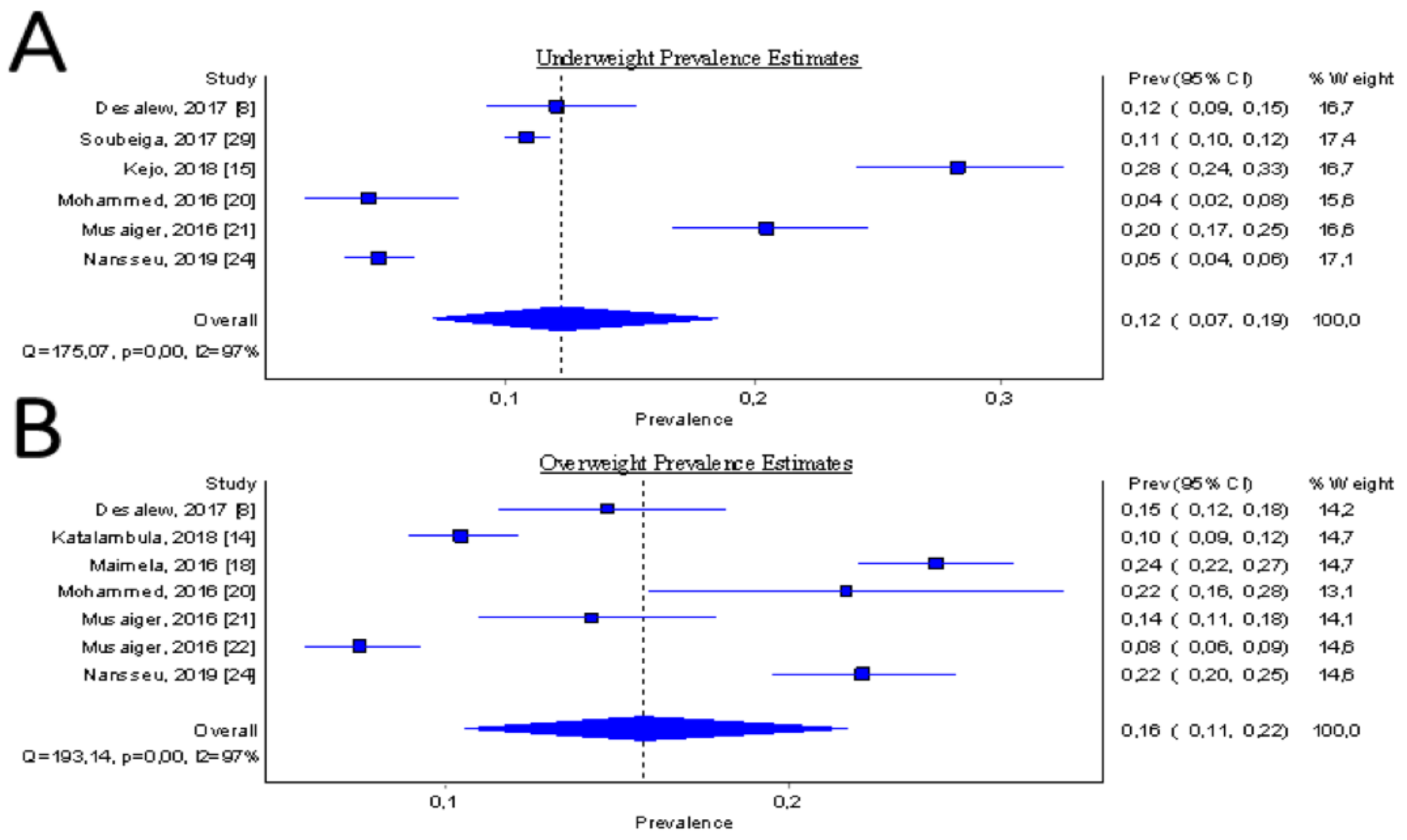

Figure 4 
Forest plot showing study-specific and pooled prevalence of being underweight and overweight in Sub-Saharan Africa, from studies published during the period 2015-2019, (a: The pooled prevalence of underweight; b: The pooled prevalence of overweight)
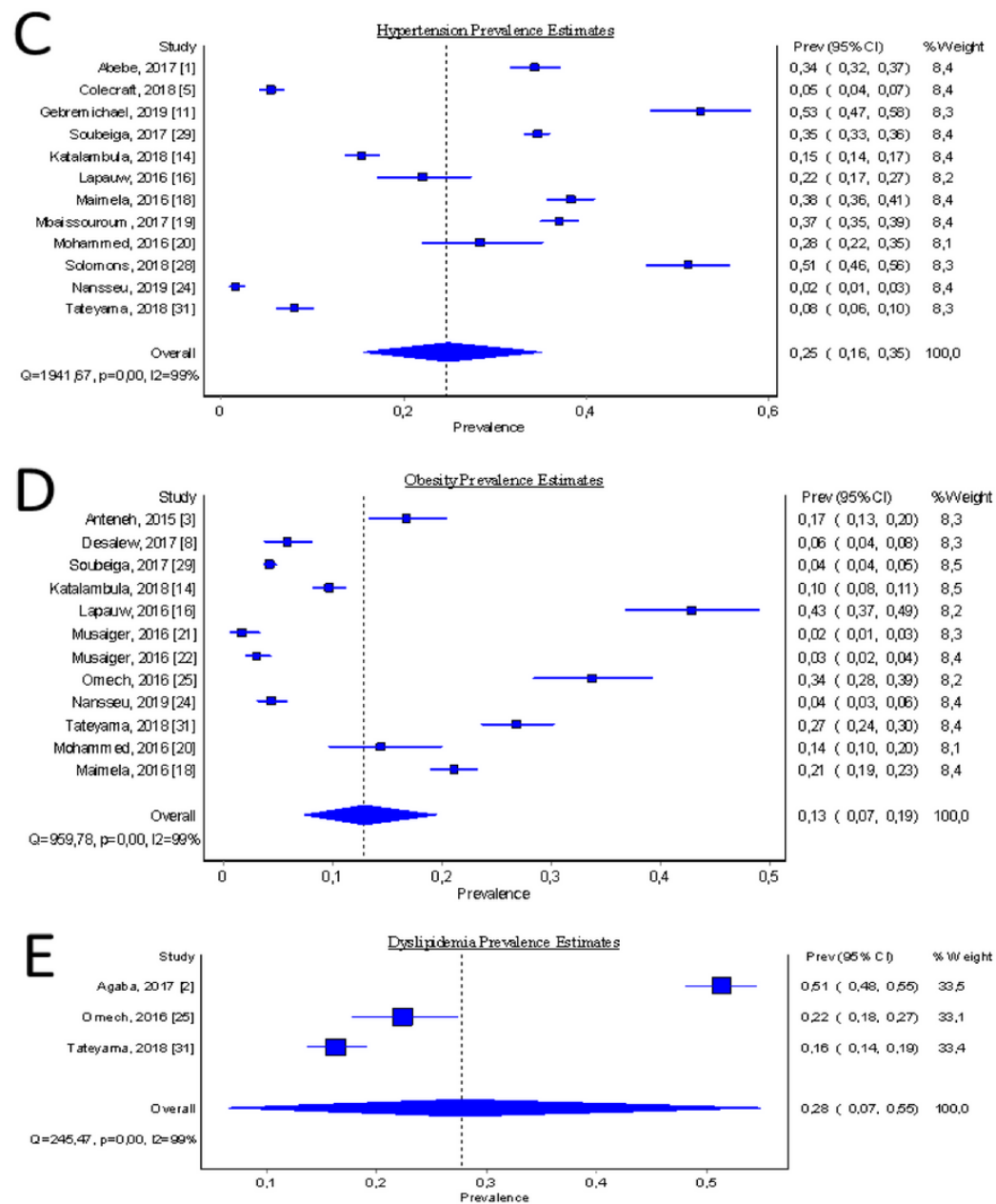

\section{Figure 5}

Forest plot showing study-specific and c: The pooled prevalence of hypertension; d: The pooled prevalence of obesity; e: The pooled prevalence of dyslipidaemia

\section{Supplementary Files}

This is a list of supplementary files associated with this preprint. Click to download.

- SupplementaryAppendixNo.1.docx

- SupplementaryAppendixNo.2.pdf 